\title{
BUB3 that dissociates from BUB1 activates caspase-independent mitotic death (CIMD)
}

\author{
Y Niikura ${ }^{1}, \mathrm{H}_{\mathrm{Ogi}}{ }^{1}, \mathrm{~K} \mathrm{Kikuchi}^{1}$ and K Kitagawa ${ }^{*, 1}$
}

The cell death mechanism that prevents aneuploidy caused by a failure of the spindle checkpoint has recently emerged as an important regulatory paradigm. We previously identified a new type of mitotic cell death, termed caspase-independent mitotic death (CIMD), which is induced during early mitosis by partial BUB1 (a spindle checkpoint protein) depletion and defects in kinetochore-microtubule attachment. In this study, we have shown that survived cells that escape CIMD have abnormal nuclei, and we have determined the molecular mechanism by which BUB1 depletion activates CIMD. The BUB3 protein (a BUB1 interactor and a spindle checkpoint protein) interacts with p73 (a homolog of p53), specifically in cells wherein CIMD occurs. The BUB3 protein that is freed from BUB1 associates with p73 on which Y 99 is phosphorylated by c-Abl tyrosine kinase, resulting in the activation of CIMD. These results strongly support the hypothesis that CIMD is the cell death mechanism protecting cells from aneuploidy by inducing the death of cells prone to substantial chromosome missegregation.

Cell Death and Differentiation (2010) 17, 1011-1024; doi:10.1038/cdd.2009.207; published online 8 January 2010

Aneuploidy - the presence of an abnormal number of chromosomes - is the primary cause of miscarriages, mental retardation, and congenital abnormalities in humans and is a hallmark of cancer. ${ }^{1}$ The role of aneuploidy in cancer has been hotly debated for almost a century, and recent evidence has shown a tight link between aneuploidy and tumorigenesis. ${ }^{2,3}$ Aneuploidy is frequently caused by chromosome missegregation during mitosis, which results from errors of the mitotic checkpoint, the major cell cycle control mechanism that prevents chromosome missegregation. ${ }^{4,5}$

The spindle checkpoint arrests cell cycle progression before anaphase if chromosomes are unattached or incorrectly attached, by transiently inhibiting the anaphasepromoting complex (APC/C). ${ }^{6,7}$ Kinetochores that are improperly attached to microtubules send a signal to the spindle checkpoint components - Mad1, Mad2, BUBR1 (Mad3-like, but has a C-terminal kinase domain), Bub1, Bub3, and Mps1 - all originally identified in Saccharomyces cerevisiae. $^{8-10}$ These components and their functions are highly conserved between yeast and humans ${ }^{11}$ and are essential for the mitotic checkpoint in human cells as bona fide mitotic checkpoint proteins. ${ }^{12,13}$

Consistent with a link between aneuploidy and cancer, several facts support the role of the spindle checkpoint in tumorigenesis. For example, mutations in the human homologs of Bub1 (BUB1 and BUBR1) have been observed in subtypes of colorectal cancer cells that exhibit chromosome instability (CIN tumor cells). ${ }^{14}$ The CIN phenotype has been associated with mutations in spindle checkpoint genes, ${ }^{15-17}$ decreased levels of spindle checkpoint proteins, ${ }^{18,19}$ and loss of spindle checkpoint activity. ${ }^{20,21} \mathrm{Mad}^{+/ /}$mice develop lung tumors at high rates after a long latency. ${ }^{22} \mathrm{Bubr1^{+/ }}$ mice and Bub3/Rae1 heterozygotes are prone to tumor development. $^{23,24}$ These results strongly suggest a close relationship between altered activity of the spindle checkpoint and tumorigenesis. Moreover, importantly, many tumor cells have a diminished, but not absent, spindle checkpoint response. ${ }^{12}$

When cells cannot satisfy the spindle checkpoint after a long mitotic delay (known as adaptation to D-mitosis), several cell fates can occur: some cells die during mitosis, some exit mitosis as viable cells but die as a result of apoptosis in the G1 phase, and some exit mitosis as viable cells but are tetraploid and reproductively dead. ${ }^{7}$ Microtubule inhibitors induce mitotic arrest by activating the spindle checkpoint; eventually, these inhibitors cause cytotoxicity. Many reports have described the cytotoxicity of microtubule inhibitors and resultant cell death as either apoptosis in G1 or reproductive death. ${ }^{25}$ However, questions regarding cell death during mitosis have remained. Although many studies suggest that cell death occurs during mitosis, ${ }^{26-30}$ the mechanism remains to be detailed, especially with regard to the relationship between the spindle checkpoint and apoptosis during mitosis.

We recently identified a novel type of mitotic cell death, which we term caspase-independent mitotic death (CIMD). ${ }^{31,32}$ Caspase-independent mitotic death is a programmed cell death in early mitosis that is induced by defects in the kinetochore-microtubule attachment in BUB1-deficient cells. In BUB1-deficient (but not MAD2 deficient) cells, CIMD is induced by conditions that activate the spindle checkpoint (i.e., cold shock or treatment with nocodazole, paclitaxel

\footnotetext{
1Department of Molecular Pharmacology, St. Jude Children's Research Hospital, 262 Danny Thomas Place, Memphis, TN 38105, USA

${ }^{*}$ Corresponding author: K Kitagawa, Department of Molecular Pharmacology, St. Jude Children's Research Hospital, 262 Danny Thomas Place, Mail Stop 230/Rm D3007C, Memphis, TN 38105-3678, USA. Tel: 901595 5371; Fax: 901595 4290; E-mail: katsumi.kitagawa@stjude.org

Keywords: aneuploidy; BUB3; c-Abl; p73; spindle checkpoint

Abbreviations: 17-AAG, 17-allylamino-17-demethoxygeldanamycin; APC/C, anaphase-promoting complex; BAF, bocaspartyl-(OMe)-fluoromethyl-ketone; B-ALL, acute B-cell lymphoblastic leukemias; CCD, charge-coupled device; CIMD, caspase-independent mitotic death; CIN, chromosome instability; CML, chronic myelogenous leukemia; FLICA, fluorochrome inhibitor of caspases; KT-MT, kinetochore-microtubule; Luc, luciferase; MEF, mouse embryonic fibroblast; siRNA, small interfering RNA; Taxol, paclitaxel; TMR, tetra-methyl-rhodamine; zVAD, Z-VAD-FMK

Received 23.1.09; revised 04.11.09; accepted 27.11.09; Edited by G Melino; published online 08.1.10
} 
(Taxol), or 17-allylamino-17-demethoxygeldanamycin (17AAG)). Caspase-independent mitotic death depends on p73, a homolog of p53, but not on p53. It also depends on the apoptosis-inducing factor (AIF) and endonuclease G (Endo $G$ ), which are effectors of caspase-independent cell death. ${ }^{33}$ When BUB1 is completely depleted, aneuploidy occurs instead of CIMD. We propose that CIMD is the cell death mechanism that protects cells from aneuploidy by inducing the death of cells prone to substantial chromosome missegregation. In this study, we determined the molecular mechanism by which CIMD is activated by partial but not complete depletion of BUB1.

\section{Results}

CIMD occurs independently of caspases. In our previous study, we detected no caspase activity (caspases 1, 3-9) in cells in which BUB1 is partially depleted using small interfering RNA (siRNA) and exposed to 17-AAG or Taxol. $^{32}$ In addition, pharmacological caspase inhibitors bocaspartyl-(OMe)-fluoromethyl-ketone (BAF) and Z-VADFMK (zVAD) did not inhibit DNA fragmentation induced by 17-AAG or Taxol treatment and BUB1 partial depletion using siRNA. $^{32}$ Therefore, we concluded that CIMD is caspase independent.

To strengthen our conclusion, we tested caspases 2 and 10-13 and observed no caspase activity in cells in which CIMD occurs (Supplementary Figure S1). We also tested whether CIMD occurs in mouse embryonic fibroblasts deficient in caspases 3 and $7^{34}$ and observed that CIMD occurs in the absence of these caspases (Figure 1a-c). These results strongly suggest that CIMD is independent of caspases.

\section{p73 depletion rescues the lethality of cells in which CIMD occurs. As we previously reported, ${ }^{32}$ when BUB1 is partially depleted from HeLa cells by siRNA and cells are subsequently treated with 17-AAG or Taxol, substantial synergistic lethality is observed in a colony outgrowth assay (Figure $2 a$ and $b$ ). We previously reported that this lethality is due to CIMD. Because the occurrence of DNA fragmentation is dependent on $\mathrm{p} 73$ but not on $\mathrm{p} 53,{ }^{32}$ we examined whether depletion of p73 rescues the lethality caused by CIMD in the colony outgrowth assay. Although we could not detect p73 in HeLa cells by immunoblotting (data not shown), the amount of $p 73 \alpha$ mRNA was significantly suppressed when two independent sets of p73 siRNAs were used (Supplementary Figure S2; Supplementary Table S2). Depletion of $p 73 \alpha$ rescued the lethality induced by BUB1 partial depletion (Supplementary Figure S3 (right panel)) and drug treatment in the colony outgrowth assay, whereas single p73 depletion and drug treatment did not cause significant lethality (Figure $2 a$ and $b$ ). These results indicate that $\mathrm{p} 73$ depletion rescues the lethality of cells in which CIMD occurs.}

Survived cells that escape CIMD have abnormal nuclei. We hypothesized that CIMD is an alternative cell death pathway that protects cells from aneuploidy by killing cells prone to substantial chromosome missegregation. ${ }^{31,32}$ If this hypothesis is true, survived cells that escape CIMD by depletion of p73 in the colony outgrowth assay should be aneuploid. There was a significant increase in the number of abnormal nuclei in cells with p73 + BUB1 double siRNA and drug (17-AAG or Taxol) treatment (Figure 2c and d). The resulting abnormal nuclei (i.e., fragmented and aggregated nuclei consisting of more than three nuclei-like fragments, micronuclei, chromosome bridges, malformed nuclei, or binuclei; Figure 2c) are similar to those of cells depleted of MAD2 for several cell divisions. ${ }^{35}$ Some abnormal nuclei types (Types 1, 2, and 3) were similar to that of completely BUB1-depleted cells that show significant reduction in CIMD cells and mitotic index with 17-AAG treatment (Supplementary Figure S3 (left panel) and S4). ${ }^{32}$

These data indicate that survived cells that escaped CIMD by the addition of p73 siRNA to BUB1 siRNA have abnormal nuclei, suggesting that CIMD eliminates cells prone to substantial chromosome missegregation. This finding strengths our hypothesis that CIMD is an alternative cell death pathway that protects cells from aneuploidy.

BUB3 interacts with $p 73 \alpha$ specifically in cells in which CIMD occurs. We proposed a working hypothesis to describe how partial depletion of BUB1 induces CIMD. ${ }^{31}$ We assume that there exists a mediator protein $X$ that interacts with BUB1. Although protein $X$ interacts with BUB1, it cannot associate with p73; when BUB1 is depleted, protein $X$ can bind to $p 73$ to activate its transcriptional activity.

As BUB3 is one of the proteins that physically interacts with BUB1, ${ }^{36,37}$ we tested BUB3 as a candidate for being protein $X$ and studied p73-BUB3 association by immunoprecipitation while introducing defects in the kinetochore-microtubule attachment (KT-MT defects) by drug treatment. Proteins were precipitated using anti- $5 \times$ His antibody from HeLa cells co-transfected with $6 \times$ His-tagged BUB3 and p73 $\alpha$ expression constructs. Taxol- or 17-AAG-treated cells and cells not treated with drugs were examined to detect this interaction. Interestingly, $\mathrm{p} 73 \alpha$ was observed in immunoprecipitates of $6 \times$ His-tagged BUB3 from 17-AAG- or Taxol-treated cells, although the level of $6 \times$ His-tagged BUB3 was below detectable levels in total lysates (Figure $3 a$ (left panel); Supplementary Figure S6). In addition, $p 73 \alpha$ was not precipitated in HeLa cells not treated with drugs (Figure $3 a$, right panel). We confirmed the occurrence of DNA fragmentation by performing TUNEL (TdT-mediated dUTP nick-end labeling) assay under the same conditions as those in which $6 \times$ His-tagged BUB3 and $\mathrm{p} 73 \alpha$ interact (Supplementary Figure S5; see the next paragraph). To check BUB3-p73 interaction in a reciprocal manner, we also performed an immunoprecipitation analysis using HeLa cells co-transfected with $6 \times$ His-tagged BUB3 and HA-tagged $p 73 \alpha$ expression constructs, and immunoprecipitated HA-tagged p73 $\alpha$ using anti-HA antibody and detected $6 \times$ His-tagged BUB3 in the immunoprecipitates (Supplementary Figure S7). Together, these data strongly suggest that BUB3 interacts with $p 73 \alpha$ specifically in cells in which CIMD occurs.

BUB3 is the mediator that induces CIMD. If our model is correct, overexpression of protein $\mathrm{X}$ should induce CIMD 
a

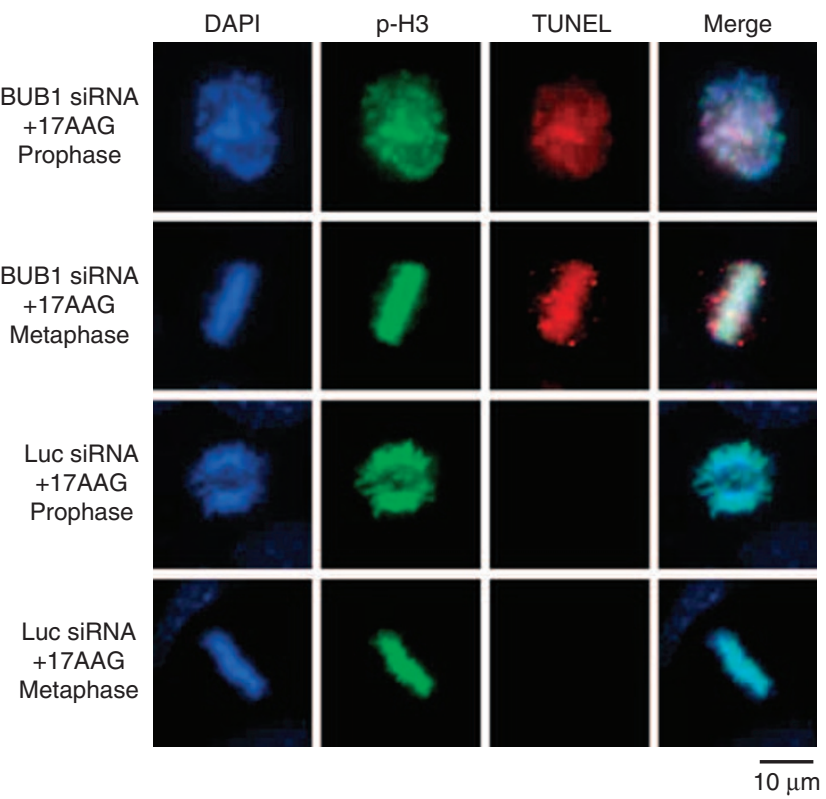

b

capase $3^{-/ /} /$caspase $7^{-/-}$MEF

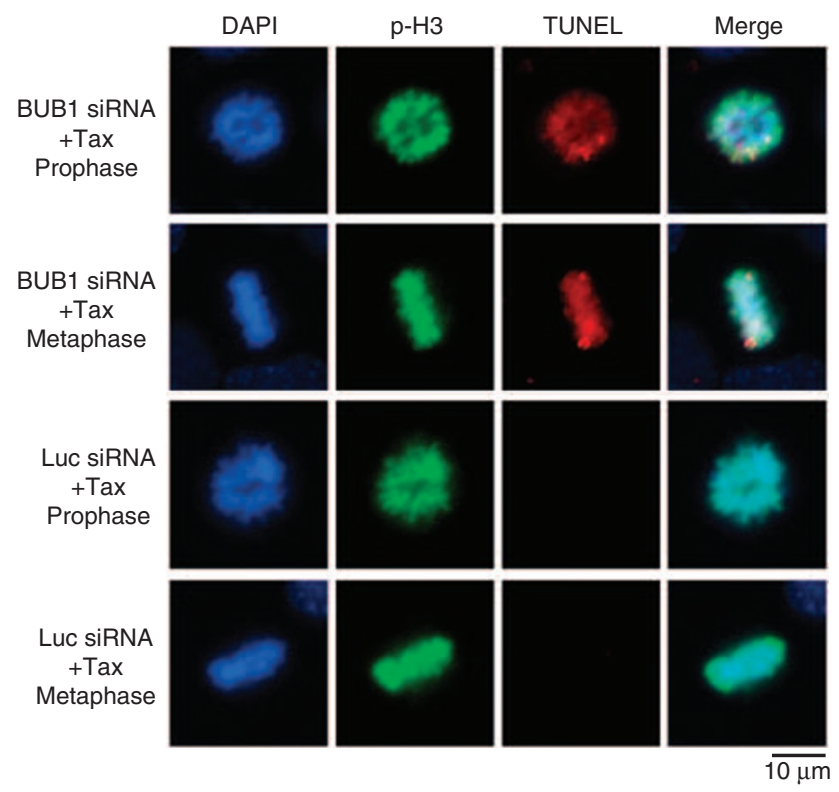

C

capase $3^{-/-} /$caspase $7^{-/-}$MEF

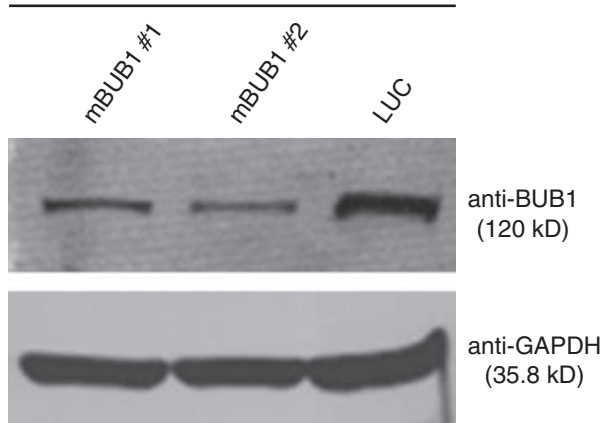

Figure 1 CIMD occurs in BUB1-depleted caspase KO cells. (a) Caspase $3^{-1-}$ caspase $7^{-1-}$ double KO MEF cells transfected with mice BUB1 siRNA and treated with 17-AAG exhibit DNA fragmentation (TUNEL ${ }^{+}$) during mitosis. At $48 \mathrm{~h}$ after caspase $\mathrm{KO}$ MEF cells were transfected with mice BUB1 siRNA, cells were incubated with 17-AAG $(+17 \mathrm{AAG}, 500 \mathrm{nM})$ or Taxol $(10 \mathrm{nM})$ for $24 \mathrm{~h}$ at $37^{\circ} \mathrm{C}$. Fixed samples were stained by using an in situ cell death detection kit that contained tetra-methyl-rhodamine (TMR) red (red), an antiphosphorylated histone $\mathrm{H} 3$ ( $\mathrm{p}-\mathrm{H} 3$ ) mouse monoclonal antibody, FITC-conjugated secondary antibodies to distinguish mitotic cells (green), and DNA was stained with DAPI (blue) to visualize prophase and metaphase cells. The scale bar represents $10 \mu \mathrm{m}$. (b) A histogram summarizing TUNEL assay results in (a). The number of TUNEL-positive cells among p-H3-positive mitotic cells in each of two independent experiments was counted, and the mean percentages ( \pm S.D.) (i.e., the number of mitotic TUNEL-positive cells per total mitotic cells) are shown. $\left.{ }^{* *}\right) P<0.001$ and $\left(^{*}\right) P<0.01$ compared with luciferase (Luc) siRNA plus no drug (Student's $t$-test). (c) Western blot analysis of total caspase $3^{-1-} /$ caspase $7^{-1}$ MEF cell lysates collected $48 \mathrm{~h}$ after transfection with mice BUB1 siRNA shows partial depletion of protein. Results from control experiments in which luciferase (Luc) siRNA was transfected into cells are shown. Glyceraldehyde-3-phosphate dehydrogenase (GAPDH) protein was the loading control

when cells are treated with drugs that generate KT-MT defects. Therefore, we overexpressed BUB3 from the Tet promoter in HeLa Tet-Off cells in the absence of tetracycline/ doxycycline (Figure $3 \mathrm{~b}$ ) and treated them with 17-AAG or Taxol. As expected, overexpression of BUB3 induced DNA fragmentation (TUNEL positive) with 17-AAG or Taxol treatment at early mitosis (Figure $3 c$ and $d$ ). There was no caspase activity (caspases 1-10 and 13) in TUNEL-positive cells (Figure $3 e$, data not shown), and caspase inhibitors BAF and $z V A D$ did not inhibit DNA fragmentation induced by 17-AAG and BUB3 overexpression (Figure $3 f$, see the study by Niikura et $a \beta^{\beta 2}$ for drug evaluation controls). Therefore, the mitotic death caused by BUB3 overexpression is caspase independent and thus CIMD.

As BUB3 overexpression induces CIMD, we next investigated whether BUB3 depletion inhibits CIMD. Although we tried achieving complete depletion of BUB3 using 11 different sets of siRNA (data not shown), we could deplete only $70 \%$ of BUB3 (Figure 3g, top panel). However, even this partial depletion of BUB3 significantly suppressed CIMD (Figure $3 g$, bottom panel). Furthermore, endogenous BUB3 interacted with p73 when BUB1 was partially depleted (Supplementary Figure S8).

These data indicate that BUB3 is the mediator protein inducing CIMD in response to KT-MT defects.

p73 isoforms and CIMD. The p73 mRNA exists as several C-terminal splice variants. ${ }^{38-47}$ As it was difficult to clearly detect endogenous levels of individual isoforms, we first depleted all isoforms by siRNA targeting the common $5^{\prime}$-UTR region (Figure $4 \mathrm{~b}$ ) and confirmed abrogation of CIMD using these siRNA sequences (Figure 4c (second 
a

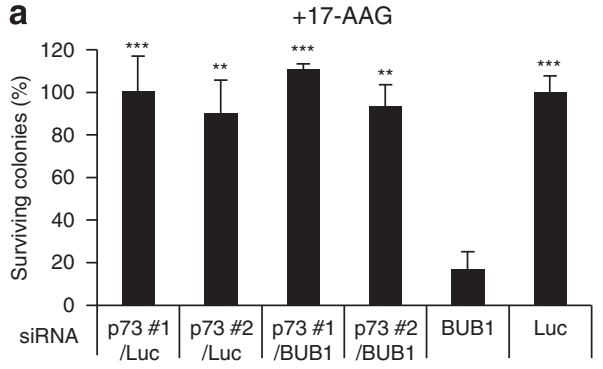

C
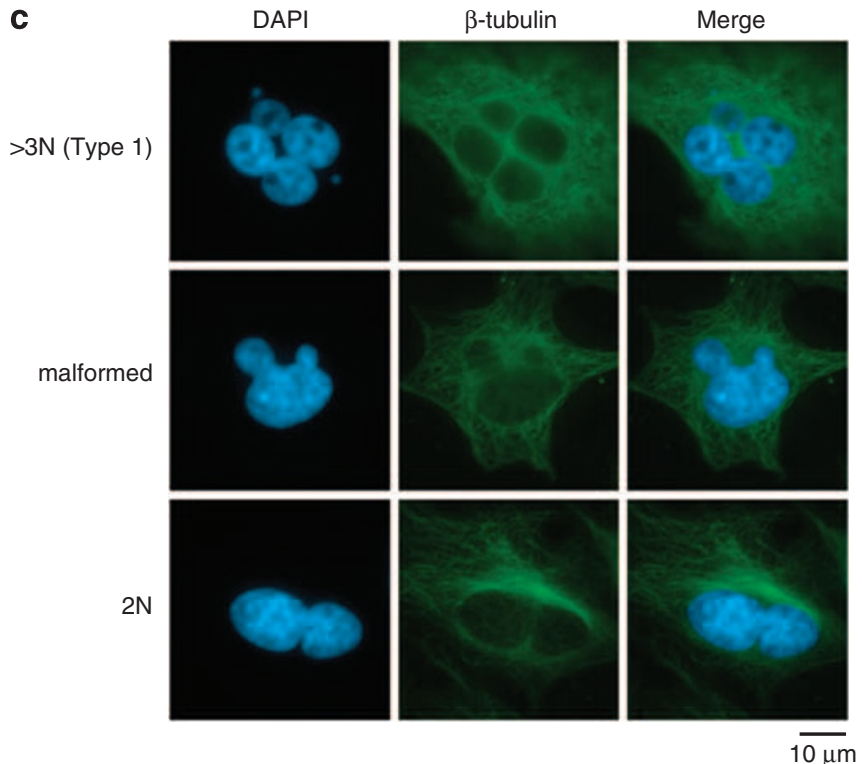

b

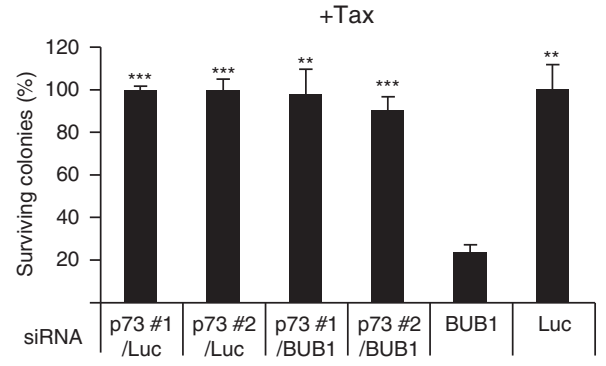

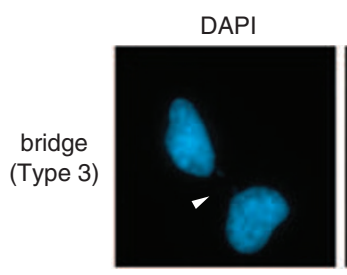

$\beta$-tubulin
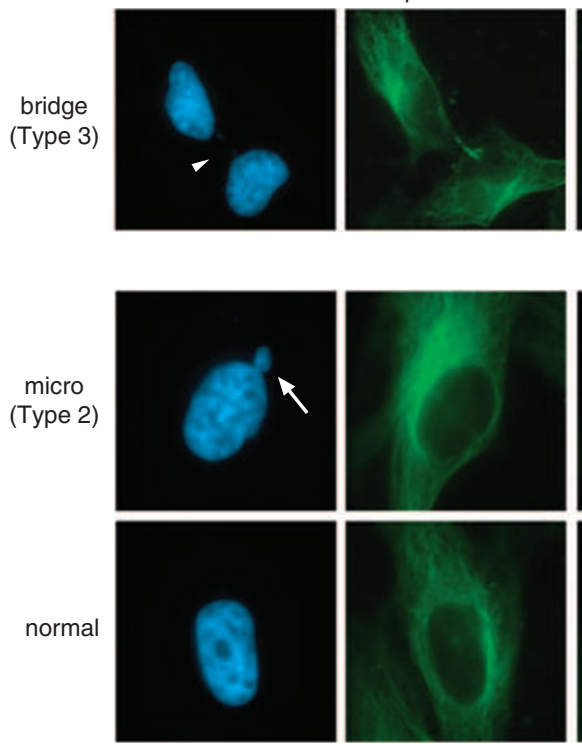

Merge

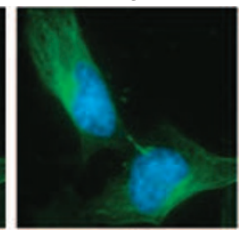

$\overline{20 \mu \mathrm{m}}$
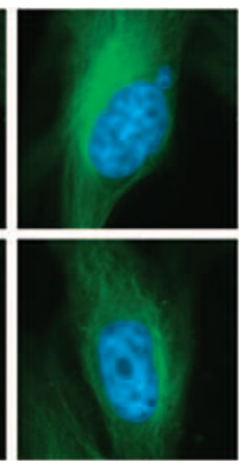

d
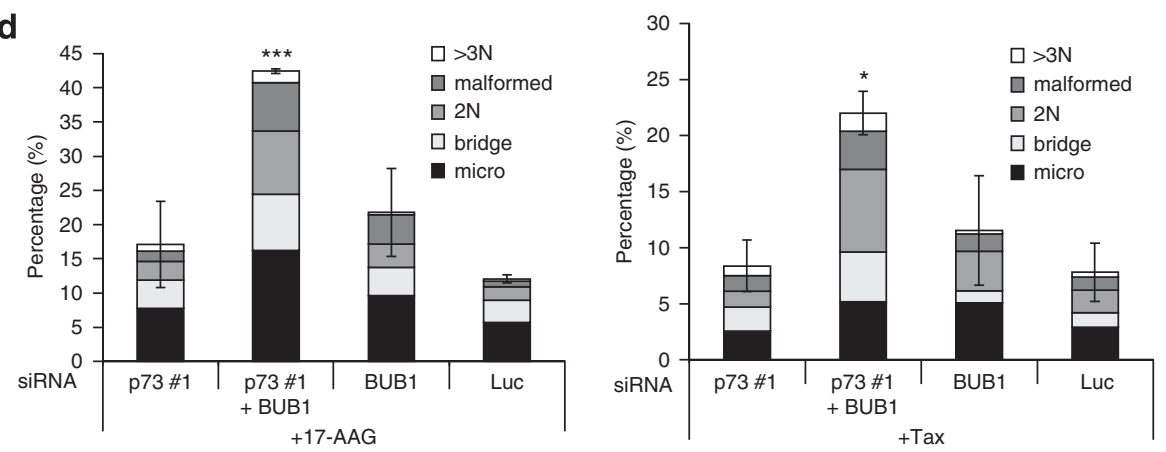

$\overline{10 \mu \mathrm{m}}$

Figure 2 p73 depletion rescues the lethality of cells in which CIMD occurs. (a and $\mathbf{b})$ p73 siRNA reduces the proportion of CIMD caused in BUB1 partially depleted cells. Colony outgrowth assays of HeLa cells transfected with siRNAs directed against p73 + Luc (luciferase), p73 + BUB1 (partial), BUB1 (partial), or Luc were conducted. At $24 \mathrm{~h}$ after transfection, cells were incubated with $100 \mathrm{nM}$ 17-AAG or $1.5 \mathrm{nM}$ Taxol for 2 days and the drug was removed by washing, but mitotic cells were retained. To allow colony formation, 500 transfected cells were spread and incubated for approximately 20 days. We normalized the percent viability - the percentage of surviving colonies in control wells (Luc siRNA plus 17-AAG (100 nM; (a)) or Taxol $(1.5 \mathrm{nM}$; (b)), which is a moderate concentration that does not kill a large proportion of the cell population (only as much as Luc siRNA plus no drug does) $-{ }^{32}$ and set it to 100 . Three independent experiments were performed for each drug, and the mean percentages ( \pm S.D.) are shown. $\left({ }^{* \star \star}\right) P<0.0001$ and $\left.{ }^{* *}\right) P<0.001$ compared with BUB1 siRNA plus drug (Student's $t$-test). (c) Survived cells that escape CIMD by p73 + BUB1 double siRNA treatment in colony outgrowth assays have abnormal nuclei. After colony formation as described in (a and $\mathbf{b})$, cells were fixed, and DNA was visualized by staining with DAPI (blue). Anti- $\beta$ tubulin ( $\beta$-tubulin; green) mouse monoclonal antibody was used to visualize the cytoskeletal structure. Types 1,2 , and 3 correspond to the overlapping types that have been previously reported. ${ }^{32}>3 \mathrm{~N}$ (type 1) refers to fragmented and aggregated nuclei and consists of more than three nuclei-like fragments; micro (type 2) refers to micronuclei (arrows); bridge (type 3) refers to chromosome bridges (arrowheads); malformed, refers to malformed nuclei; 2N, refers to binuclei; and normal, refers to normal-shaped nuclei. Bar:, $10 \mu \mathrm{m}$ or $20 \mu \mathrm{m}$. (d) A histogram summarizing abnormal nuclei in (c). Three independent experiments were performed for each drug, and the mean percentages ( \pm S.D.) are shown. $\left(^{* *}\right) P<0.0001$ and $\left(^{*}\right) P<0.01$ compared with Luc siRNA plus drug (Student's $t$-test)

column from the right); Supplementary Table S2). We then expressed each isoform (Figure 4a) to determine the ones that complemented the function of p73 in CIMD. Interestingly, the expression of $\alpha-, \beta-$, and $\gamma$-isoforms, but not of the $\varepsilon$-isoform, induced CIMD (Figure 4c). 
However, under conditions in which CIMD occurs, BUB3 interacted with $\alpha-, \beta-, \gamma$-, and $\varepsilon$-isoforms (Figure $4 d$ ), suggesting that binding of p73 isoforms to BUB3 is not sufficient to induce CIMD.

Tomasini et al. ${ }^{48}$ described two independent promoters that enable expression of full-length, transcriptionally competent proteins (TAp73 isoforms) and amino-truncated transcriptionally incompetent proteins ( $\Delta \mathrm{Np} 73$ isoforms). Furthermore, extensive $3^{\prime}$ splicings generate further isoforms for each TAp73 and $\Delta N p 73$ isoform. ${ }^{39,48} \Delta N p 73$ isoforms, by inhibiting the transactivational activity of both TAp73 and p53, are antiapoptotic and therefore oncogenic. ${ }^{48}$ We observed that $\Delta \mathrm{Np} 73 \alpha, \beta$, and $\gamma$ suppressed DNA fragmentation in BUB1depleted cells that were treated with 17-AAG (Figure 4e), indicating that $\triangle \mathrm{Np} 73$ isoforms inhibit CIMD.

Y99 phosphorylation on $\mathrm{p} 73 \alpha$ by c-Abl tyrosine kinase is required for CIMD activation. Previous studies report that when p73 is activated in response to DNA damage, p73 Y99 is phosphorylated by c-Abl (human ABL1) tyrosine kinase. ${ }^{49}$ This phosphorylation is a prerequisite modification for p73 to elicit cell death in fibroblasts. ${ }^{49,50}$

In our study, phosphorylated Y99 was detected with antiphospho-p73 $\alpha$ (Y99)-specific antibody, specifically in $6 \times$ HisBUB3 immunoprecipitates (Figure 5a; Supplementary Figure S6), indicating that Y99-phosphorylated p73 interacts with BUB3 in cells in which CIMD occurs.

To investigate the role of $Y 99$ phosphorylation on $p 73 \alpha$ in CIMD activation, we constructed an unphosphorylated mutant p73 $\alpha$-Y99A. The p73 $\alpha$-Y99A mutant was expressed at the same level as the wild-type control (Figure $5 \mathrm{~b}$, top panel), and it significantly suppressed the CIMD induced by BUB3 overexpression plus 17-AAG or Taxol treatment (Figure 5b, bottom panel). These data strongly suggest that Y99 phosphorylation on $\mathrm{p} 73 \alpha$ is required for CIMD activation.

As p73 is phosphorylated at Y99 by c-Abl, we examined whether $\mathrm{c}-\mathrm{Abl}$ is required for CIMD. The depletion of $\mathrm{c}-\mathrm{Abl}$ (Figure 5c, top panel) significantly suppressed CIMD (Figure 5c, bottom panel). Moreover, c-Abl kinase inhibitors, imatinib and dasatinib, inhibited CIMD (Figure 5d). These results indicate that $\mathrm{c}-\mathrm{Abl}$ tyrosine kinase is required for CIMD, indicating a new role for $\mathrm{c}$-Abl in protecting cells from aneuploidy by inducing programmed cell death that occurs during mitosis.

S19 phosphorylation on BUB3 by BUB1 kinase is required for CIMD activation. As BUB1 kinase activity is required to induce $\mathrm{CIMD},{ }^{32}$ we hypothesized that BUB3 might be phosphorylated by BUB1 to activate p73. First, we examined whether BUB1 phosphorylates BUB3 in vitro. We performed BUB1 kinase assay using histone $\mathrm{H} 3$ as a positive control (Figure 6a) and observed that BUB3 was phosphorylated by BUB1 in vitro (Figure 6a). Mass spectrometry analysis revealed that BUB3 is phosphorylated at serine-19 (S19) by BUB1 in vitro (Figure 6b). To confirm whether this phosphorylation occurs in vivo, we performed 2D-gel electrophoresis and immunoblotting. Alkaline phosphatase treatment of immunopurified BUB3 reduced the intensity of the signal of the dot at the far right of BUB3 (Figure 6c, top (arrow and circle) and middle panels), indicating that this dot is a phosphorylated form of BUB3. We observed that the corresponding dot was absent in an unphosphorylated mutant BUB3-S19A (Figure 6c, bottom panel), suggesting that $\mathrm{S} 19$ is phosphorylated in vivo. Importantly, overexpression of wild-type BUB3 but not of the S19A mutant induced CIMD (Figure 6d), indicating that $\mathrm{S} 19$ phosphorylation on BUB3 is required for CIMD activation. However, the BUB3-S19A mutant protein was able to associate with $p 73 \alpha$ as the wild-type BUB3 protein, indicating that $\mathrm{S} 19$ phosphorylation is not necessary for interaction with p73 (Figure 6e).

\section{Discussion}

The molecular mechanism involved in the activation of CIMD has not been elucidated to date. Here, we show that overexpressed BUB3, a BUB1 interactor, interacts with p73, a structural and functional homolog of the p53 tumorsuppressor protein, specifically in cells in which CIMD occurs. Y99 phosphorylation on $\mathrm{p} 73$ by c-Abl tyrosine kinase and S19 phosphorylation on BUB3 by BUB1 kinase are required for CIMD activation. These results strengthen the hypothesis that CIMD protects cells from aneuploidy, which leads to tumorigenesis.

Molecular mechanism of activation of CIMD. To explain how partial BUB1 depletion induces CIMD, our initial hypothesis was that BUB1 phosphorylates p73 to activate it, but binding of BUB1 to p73 silences the transcriptional activity of $p 73$. Therefore, a certain level of BUB1 is needed to phosphorylate p73, but this level should be low enough to release phosphorylated p73 from BUB1 to bind DNA. However, we could not detect the BUB1-p73 interaction by immunoprecipitation under various conditions. Therefore, we proposed another hypothesis that suggests that activated BUB1 binds to mediator protein $\mathrm{X}$ and phosphorylates it. ${ }^{31}$ According to this model, overexpression of mediator protein $X$ should induce CIMD. Our results clearly demonstrate that BUB3 interacts with $p 73 \alpha$ specifically (Figures $3 \mathrm{a}$ and $5 \mathrm{a}$, Supplementary Figures S6-8) and Y99-phosphorylated p73 interacts with BUB3 in cells in which CIMD occurs (Figures 5a; Supplementary Figures S5 and S6). Therefore, we conclude that BUB3 is the mediator protein X (Figure 7).

A molecular switch should be required to modify BUB3 to activate p73 to induce CIMD conditionally. As BUB1 kinase activity is required to induce $\mathrm{CIMD},{ }^{32}$ we tested whether BUB3 is phosphorylated by BUB1. Serine-19 on BUB3 was phosphorylated by BUB1 in vitro (Figure $6 a$ and b) and this site was phosphorylated in vivo (Figure 6c). Overexpression of an unphosphorylated mutant BUB3-S19A protein, but not BUB3, failed to induce CIMD, indicating that S19 phosphorylation is required for CIMD (Figure 6d). However, we observed that BUB3-S19A protein was able to bind $\mathrm{p} 73 \alpha$ efficiently (Figure 6e). Therefore, there may be additional modification to regulate the BUB3-p73 association.

p73 isoforms. Several studies have suggested specific roles for particular p73 isoforms. ${ }^{38,42,48,51,52}$ The p73 mRNA exists as several C-terminal splice variants. ${ }^{38-47}$ 
Tomasini et al. ${ }^{48}$ described two independent promoters that enable expression of full-length, transcriptionally competent proteins (TAp73 isoforms) and amino-truncated transcriptionally incompetent proteins ( $\Delta \mathrm{Np} 73$ isoforms). Furthermore, extensive $3^{\prime}$ splicings generate further isoforms for each TAp73 and $\Delta \mathrm{Np} 73$ isoform. ${ }^{39,48}$ Tomasini et al. $^{48}$ reported that as TAp73 isoforms can transactivate similar proapoptotic genes, such as p53, they can act as tumor suppressors; however, $\Delta \mathrm{Np} 73$ isoforms, by inhibiting the transactivational activity of both TAp73 and p53, are a

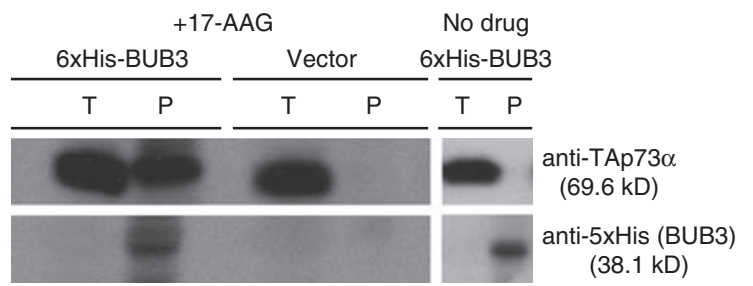

b

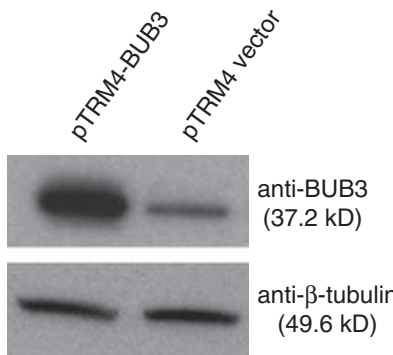

C

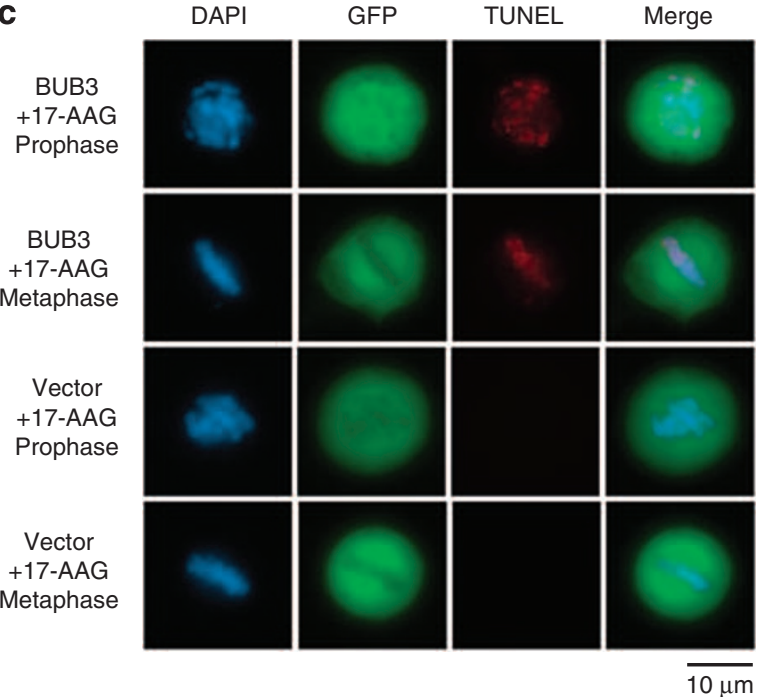

d

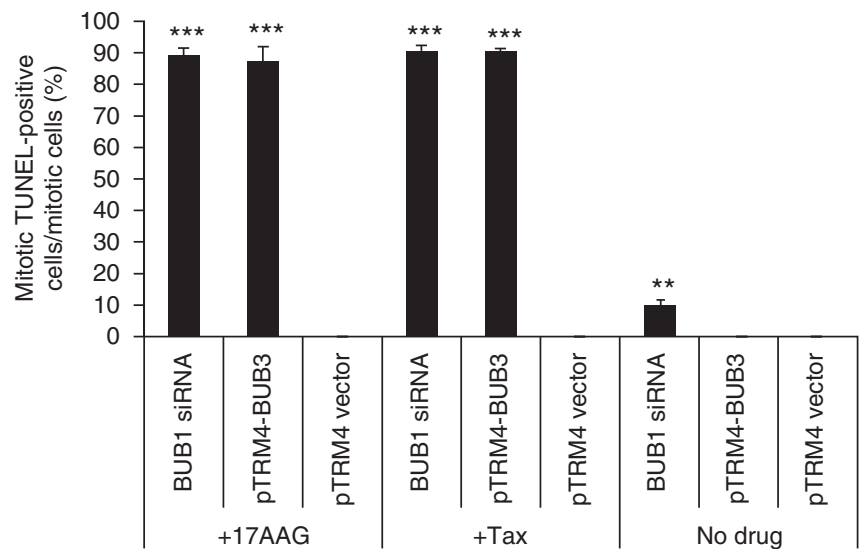

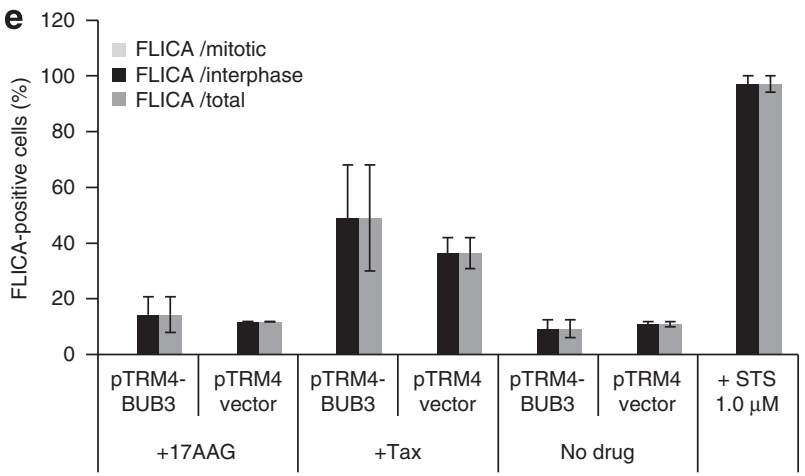

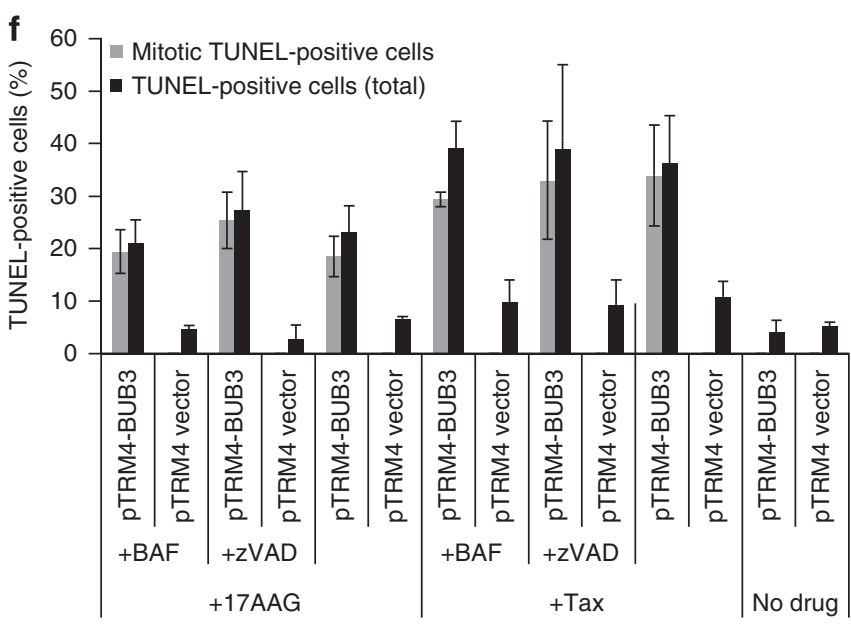

g
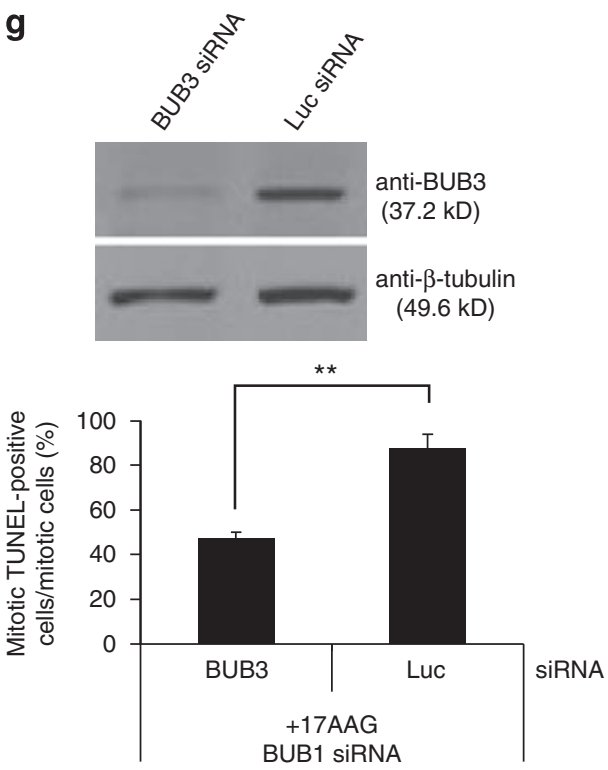
antiapoptotic and therefore oncogenic. ${ }^{48}$ The first study of p73-deficient mice $\left(\operatorname{Trp}^{-1-}\right)$ by Yang et al. ${ }^{53}$ showed that they have neurological, pheromonal, and inflammatory defects but lack spontaneous tumors. However, Flores et al. ${ }^{54}$ reported that $\mathrm{p} 73^{+/-}$mice had spontaneous tumors, and 6 of $10 \mathrm{p} 73^{-/}$mice had spontaneous lung adenocarcinoma, which is not consistent with the findings of Yang et $a .^{53} \mathrm{~A}$ recent study also showed that mice specifically lacking TAp73 isoforms exhibit spontaneous and carcinogen-induced tumors, infertility, and aging, as well as hippocampal dysgenesis. ${ }^{52}$ Interestingly, cells from $\mathrm{TAp} 3^{-1-}$ mice exhibit genomic instability associated with enhanced aneuploidy, which may explain the increased incidence of spontaneous tumors in these mutants. Therefore, TAp73 isoforms have a tumor-suppressive role and Trp73 may be involved in maintaining genomic stability.

We used siRNA sequences targeting the $p 73 \alpha$ isoform and confirmed the reduction of $\mathrm{p} 73 \alpha$ by RT-PCR (Supplementary Figure S2; Figure 4b). As it was difficult to confirm the specific depletion of each isoform, we expressed each isoform when all isoforms were depleted (Figure $4 \mathrm{a}$ and b). Interestingly, overexpression of $\alpha-, \beta$-, and $\gamma$-but not the $\varepsilon$-isoform was sufficient to induce CIMD (Figure 4c). However, $\alpha-, \beta-, \gamma-$, and $\varepsilon$-isoforms interacted with BUB3 (Figure $4 d$ ). The $\varepsilon$-isoform bound to BUB3 but could not induce CIMD, suggesting that specific regions of $\alpha-, \beta$-, and $\gamma$-isoforms are important for CIMD activation. Further analysis is required to determine these specific domains and their functions. We also observed that $\Delta \mathrm{Np} 73$ isoforms inhibit TAp73 forms in CIMD activation
(Figure $4 e),{ }^{40}$ raising the possibility that CIMD does not occur in cancer cells expressing $\Delta \mathrm{Np} 73$, such as neuroblastoma cells, which exhibit aneuploidy. ${ }^{55,56}$

p73, the spindle checkpoint, and aneuploidy. We observed that under the conditions in which CIMD occurs, p73 interacts with BUB3 but not with BUB1. However, very recently, Vernole et al. ${ }^{57}$ reported that $p 73 \alpha$ binds to BUB1 and BUB3 in colchicine-treated cells, and Tomasini et al. ${ }^{58}$ observed that $p 73 \alpha$ interacts with BUBR1 and a C-terminal fragment of BUB1 interacts with $\mathrm{p} 73 \alpha$ in nocodazole-treated cells. We do not know the reason for this disparity, but the fact that they used the conditions under which CIMD occurred in our studies could be an important factor. For example, both studies overexpressed these proteins to study interactions in the presence of microtubule inhibitors, 57,58 and we know that overexpression of BUB3 causes CIMD when cells are treated with microtubule inhibitors. Tomasini et al. $^{52}$ also report a putative function of p73 in the spindle checkpoint activity; however, the premature mitotic exit that they observed in nocodazole-treated $\mathrm{TAp}^{-1-}$ cells was minor compared with that seen in authentic spindle checkpoint mutant/depleted cells. This minor defect can be explained by loss of CIMD in p73 knockdown cells (Figure 2). Further analysis is required to clarify these issues.

Defects in the spindle checkpoint can promote aneuploidy, and an altered checkpoint is common in tumor cells. ${ }^{3,12}$ Various mutations have been identified in spindle checkpoint components, ${ }^{3,12}$ but no correlation has been established

Figure 3 BUB3 interacts with TAp73 $\alpha$ specifically in cells in which CIMD occurs. (a) Immunoblot analysis of BUB3 immunoprecipitates. Plasmids pDEST26-6 $\times$ Hishuman BUB3 and pcDNA3-human TAp73 $\alpha$ were co-transfected into HeLa cells. At $48 \mathrm{~h}$ after transfection, HeLa cells were incubated with $500 \mathrm{nM}$ 17-AAG for $24 \mathrm{~h}$ ( + 17-AAG) or not incubated with drug (no drug), and protein extracts were prepared. Proteins in the total cell lysate (T) and precipitate (P) obtained by using Ni-NTA agarose purification were detected using p $73 \alpha$ antibody. The volume of the total cell lysate was $12 \%$ of that of the starting material. (b) HeLa Tet-Off cells in the absence of tetracycline/ doxycycline, which expressed pTRM4-human BUB3, were immunoblotted using anti-BUB3 antibody. Protein extracts were prepared $48 \mathrm{~h}$ after transfection. $\beta$-Tubulin protein was the loading control. (c) Overexpression of BUB3 induces CIMD. HeLa Tet-Off cells in the absence of tetracycline/doxycycline, which expressed pTRM4-human BUB3 and were treated with 17-AAG, exhibit DNA fragmentation (TUNEL ${ }^{+}$) during mitosis. At $48 \mathrm{~h}$ after HeLa cells were co-transfected with plasmid pEGFP-N1, as the transfection marker, plus pTRM4-human BUB3, cells were incubated with 17-AAG ( + 17AAG, $500 \mathrm{nM}$ ) or Taxol (10 nM, pictures not shown) for $24 \mathrm{~h}$ at $37^{\circ} \mathrm{C}$. Fixed samples were stained using an in situ cell death detection kit that contained tetra-methyl-rhodamine (TMR) red (red) and an anti-GFP rabbit polyclonal antibody and FITC-conjugated secondary antibodies (green). DNA was stained with DAPI (blue) to visualize prophase and metaphase cells. The scale bar represents $10 \mu \mathrm{m}$. (d) A histogram summarizing TUNEL assay results in (c). The number of TUNEL-positive cells among more than 100 GFP-positive mitotic cells in each of the three independent experiments was counted, and the mean percentages $( \pm$ S.D.) (i.e., the number of mitotic TUNEL-positive cells per total GFP-positive mitotic cells) are shown. Samples of BUB1 siRNA (partial) plus drug treatment were the positive controls. $\left({ }^{* *}\right) P<0.0001$ and $\left({ }^{* *}\right) P<0.001$ compared with pTRM4 vector plus no drug (Student's $t$-test). (e) Mitotic cell death induced by BUB3 overexpression plus 17-AAG or Taxol treatment does not activate caspases. At $48 \mathrm{~h}$ after co-transfection of HeLa Tet-Off cells in the absence of tetracycline/doxycycline with a plasmid pEGFP-N1 + pTRM4-human BUB3, cells were incubated with 17-AAG (+17AAG, $500 \mathrm{nM})$ or Taxol $(+$ Tax, $10 \mathrm{nM})$ for $24 \mathrm{~h}$ at $37^{\circ} \mathrm{C}$. As a positive control, HeLa cells were treated with $1 \mu \mathrm{M}$ staurosporine ( + STS) for $6 \mathrm{~h}$. Cells were incubated in the SR-VAD-FMK fluorochrome inhibitor of caspases (FLICA) solution for $60 \mathrm{~min}$ at $37^{\circ} \mathrm{C}$ to detect activated caspases 1 and 3-9. Samples were examined under a fluorescent microscope, and the number of FLICA-positive cells, among more than 200 GFP-positive cells in each of three independent experiments, was counted. The calculated mean percentages are shown. Black bars represent the mean percentages ( \pm S.D.) of interphase FLICA-positive cells, whereas the dark gray bars indicate the mean percentage ( \pm S.D.) of all FLICA-positive cells. No mitotic FLICA-positive cells (light gray bars) were observed. (f) Pan-caspase inhibitors, bocaspartyl-(OMe)-fluoromethyl-ketone (BAF; $50 \mu \mathrm{M})$ or Z-VAD-FMK (ZVAD; $50 \mu \mathrm{M})$, do not suppress mitotic cell death induced by BUB3 overexpression plus 17-AAG or Taxol treatment. Samples were examined under a fluorescent microscope, and more than 200 GFP-positive cells in each of three independent experiments were counted. Gray bars represent the mean percentages ( \pm S.D.) of mitotic TUNEL-positive cells, whereas black bars indicate the mean percentage ( \pm S.D.) of all TUNEL-positive cells. Cell culture, transfection, 17-AAG or Taxol treatment, and TUNEL-staining were performed as described in $\mathbf{c}$ and d. Pancaspase inhibitors, BAF $(50 \mu \mathrm{M})$ or ZVAD $(50 \mu \mathrm{M})$, were applied $1 \mathrm{~h}$ before 17-AAG or Taxol treatment, and the inhibitors remained in the medium during 17-AAG or Taxol treatment. (g) (Top panel) Western blot analysis of total HeLa cell lysates collected $48 \mathrm{~h}$ after transfection with siRNA duplexes directed against BUB3 shows partial depletion of protein. Results from control experiments in which luciferase (Luc) siRNA was transfected into cells are shown. $\beta$-Tubulin protein was the loading control. (Bottom panel) Partial depletion of BUB3 suppresses CIMD induced by BUB1 partial depletion significantly. The histogram summarizes TUNEL assay results of BUB3 partially depleted cells. At $48 \mathrm{~h}$ after HeLa cells were transfected with BUB1 (partial) + BUB3 siRNA or BUB1 (partial) + Luc siRNA, they were incubated with 17-AAG $(+17 \mathrm{AAG}, 500 \mathrm{nM}$ ) for $24 \mathrm{~h}$ at $37^{\circ} \mathrm{C}$. TUNEL staining was performed as described in $\mathbf{c}$ and $\mathbf{d}$. Caspase-independent mitotic death induced by BUB1 partial depletion, as reported previously ${ }^{32,}$ (right column) was significantly suppressed (left column). The number of TUNEL-positive cells among more than 100 mitotic cells in each of three independent experiments was counted, and the mean percentages ( \pm S.D.) (i.e., the number of mitotic TUNEL-positive cells per total mitotic cells) are shown. $\left.{ }^{* *}\right) P<0.001$ compared with BUB1 (partial) + Luc siRNA plus 17-AAG (Student's t-test) 
a
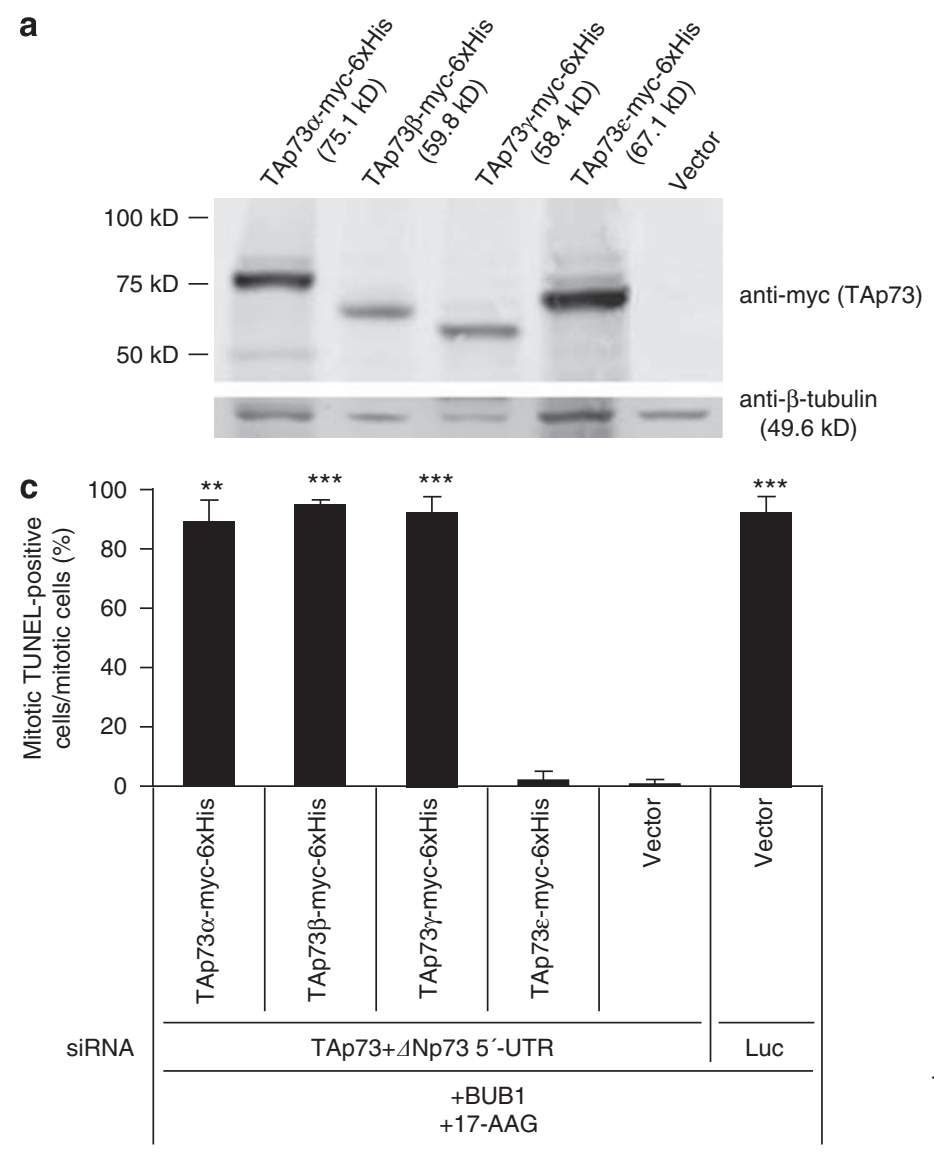

d

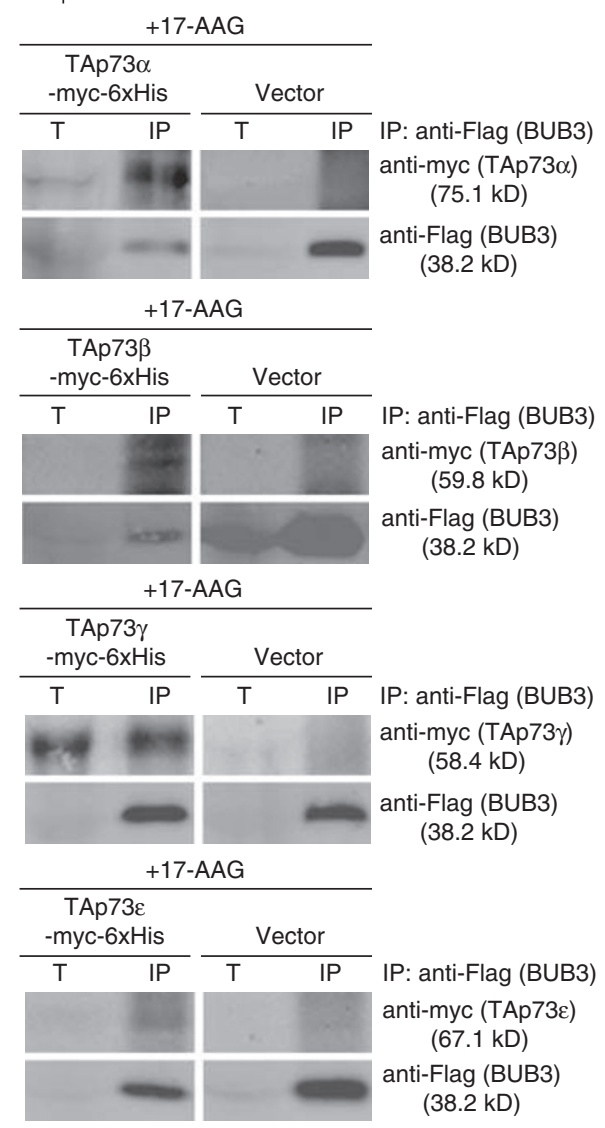

b
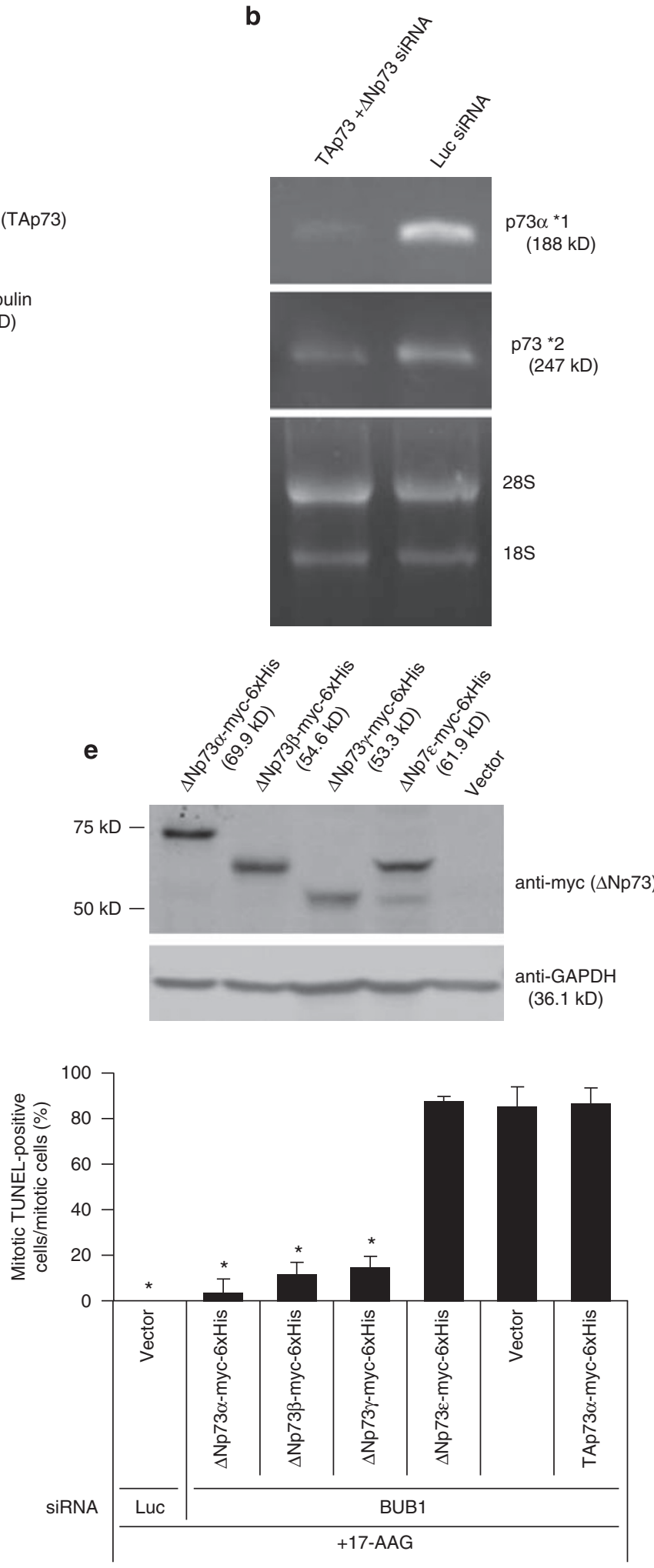
between mutations and protein function. Some studies have found that levels of checkpoint components are different in tumor and normal cells, ${ }^{59-62}$ but there is no consensus on whether levels of specific proteins increase or decrease in tumor cells and how altered expressions affect the spindle checkpoint function. Our results and previous studies suggest that the expression and balance in levels of BUB1 and BUB3 are important to induce CIMD. ${ }^{32,63}$ Thus, it would be interesting to detect the balances of these proteins in cancer cells.

p73 Y99 phosphorylation and the role of c-Abl in CIMD. Tyrosine kinase $\mathrm{c}-\mathrm{Abl}$ is the cellular proto-oncogenic counterpart of oncogenic BCR-ABL, ${ }^{64,65}$ which is the fusion gene product of the Philadelphia $(\mathrm{Ph})$ chromosome generated from a reciprocal translocation between chromosome 9 containing the tyrosine kinase $c-A b l$ and chromosome 22 with the BCR gene (t[9;22]). ${ }^{66,67} \mathrm{BCR}-\mathrm{ABL}$ tyrosine kinase activity is essential to induce in vitro cellular transformation ${ }^{68}$ and in vivo leukemogenesis. ${ }^{69,70}$ Deregulated activity of BCR-ABL tyrosine kinase is responsible for the development of $90 \%$ of chronic myelogenous leukemia cases and $5-15 \%$ of acute B-cell lymphoblastic leukemias. ${ }^{71}$ The $\mathrm{c}$-Abl protein is also activated by certain DNA-damaging agents ${ }^{72}$ and can induce programmed cell death (apoptosis) through p53dependent and p53-independent mechanisms. ${ }^{73}$ The p73 protein is regulated by tyrosine kinase $\mathrm{c}-\mathrm{Abl}$ in the apoptotic response to DNA damage. ${ }^{49}$ In our study, Y99phosphorylated p73 interacted with BUB3 in cells in which CIMD occurs (Figure 5a; Supplementary Figures S5 and S6); in addition, expression of the p $73 \alpha-Y 99 A$ mutant significantly suppressed CIMD induced by BUB3 overexpression plus drug treatment (Figure $5 b$ ) and $c-A b l$ tyrosine kinase and its activity were required for CIMD (Figure $5 \mathrm{c}$ and d). These data support the idea that $\mathrm{c}$-Abl has an important role in inducing programmed cell death during mitosis.
In vivo function of CIMD. Jeganathan et al. ${ }^{63}$ generated a series of mutant mice with a gradient of reduced Bub1 expression, using wild-type, hypomorphic, and knockout alleles. They observed that Bub1-hypomorphic, but not Bub1-haploinsufficient, mice are highly susceptible to spontaneous tumors.

We speculate that the loss of generation of spontaneous tumors in Bub1-haploinsufficient mice may be due to CIMD. This hypothesis should be tested using mouse embryonic fibroblast (MEF) cells derived from Bub1 mutant mice ${ }^{63,74}$ and determining whether CIMD occurs. If spontaneous tumorigenesis in Bub1 ${ }^{+/-}$mice is suppressed by CIMD, then reduction or deletion of $\mathrm{p} 73$ in Bub1 ${ }^{+/}$mice should increase spontaneous tumorigenesis. These genetic analyses will determine the in vivo function of CIMD. Caspase-independent mitotic death has also been observed to be dependent on AIF and Endo $G$, which are effectors of caspase-independent cell death, ${ }^{33}$ and EndoG and Aif double-knockout mice can be used to test whether CIMD prevents tumorigenesis. Physiological studies on CIMD in mouse models can help determine the in vivo function of CIMD.

\section{Materials and Methods}

Antibodies and reagents. Supplementary Table S1 lists the antibodies used, Supplementary Table S2 lists the siRNA/shRNA sequences, Supplementary Table S3 lists the plasmid vectors, Supplementary Table S4 lists the drugs, Supplementary Table S5 lists the cell lines, and Supplementary Table S6 lists the DNA oligonucleotide primer sequences used in this study. Custom-made siRNA and DNA oligonucleotide primers were synthesized by the Hartwell Center for Bioinformatics and Biotechnology, St. Jude Children's Research Hospital, Memphis, TN, USA.

Cell culture and transfection. HeLa cells or HeLa Tet-Off cells (Clontech, Mountain View, CA, USA) were cultured in high-glucose Dulbecco's modified Eagle's medium (BioWhittaker, Walkersville, MD, USA) with $10 \%$ fetal bovine serum (FBS) (Invitrogen, Carlsbad, CA, USA) and $1 \mathrm{mM}$ penicillin-streptomycin. Caspase $3^{-l-}$ caspase $7^{-1-}$ MEF cells were cultured in high-glucose Dulbecco's modified Eagle's medium (BioWhittaker) with 10\% FBS (Invitrogen),

Figure 4 Distinctive function of TAp73 isoforms and $\triangle N p 73$ isoforms in CIMD. (a) Overexpression of TAp73 isoforms. HeLa cells were transfected with either empty vector or expression plasmids encoding each isoform of TAp73 (pcDNA3-DEST-human TAp73 $\alpha-\varepsilon$-myc- $6 \times$ His), as indicated. Western blot analysis of total HeLa cell lysates collected $48 \mathrm{~h}$ after transfection was performed. $\beta$-Tubulin protein was the loading control. (b) siRNA targeting of all the isoforms of p73. Cellular levels of $p 73 \mathrm{mRNA}$ were examined by RT-PCR from HeLa cells. Cells were transfected with an siRNA mixture that targets $5^{\prime}$-UTR of all p73 isoforms (TAp73 $+\triangle N$ Np73 siRNA; see Supplementary

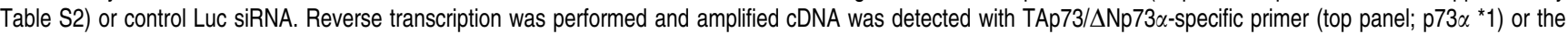
common region primer of all the TAp73/ $\Delta$ Np73 isoforms (middle panel; $p 73{ }^{*} 2$ ). Total RNA was the loading control (bottom panel). (c) Overexpression of TAp73 $\alpha, \beta, \gamma$, but not $\varepsilon$, rescues the CIMD phenotype when all p73 isoforms are depleted. The histogram summarizes results of the TUNEL assay of cells partially depleted of BUB1. At $48 \mathrm{~h}$ after HeLa cells were co-transfected with the plasmid pEGFP-N1 as transfection marker, as well as with overexpression vector of each TAp73 isoform (as shown in Figure 4a), TAp73 $+\triangle$ Np73 5'-UTR siRNA (as shown in Figure 4b), and BUB1 siRNA (partial), they were incubated with 17-AAG ( $+17 A A G, 500 \mathrm{nM}$ ) for $24 \mathrm{~h}$ at $37^{\circ} \mathrm{C}$. Cells transfected with Luc siRNA and/or vector were used as control. TUNEL staining was performed as described in Figure $3 \mathrm{c}$ and $\mathrm{d}$. The number of TUNEL-positive cells among GFP-positive mitotic cells in each of two independent experiments was counted, and the mean percentages ( \pm S.D.) (i.e., the number of mitotic TUNEL-positive cells per total GFP-positive mitotic cells) are shown. $\left(^{\star \star \star}\right) P<0.0001$ and $\left(^{\star \star}\right) P<0.001$ compared with vector plus TAp73 $+\Delta$ Np73 $5^{\prime}$-UTR siRNA plus BUB1 siRNA (partial) plus 17-AAG (Student's t-test). (d) TAp73 $\alpha, \beta, \gamma$, and $\varepsilon$ interact with BUB3 in which CIMD occurs. Immunoblot analysis of BUB3 immunoprecipitates was performed. Plasmid pDEST26-6 $\times$ His-human BUB3 and each TAp73 isoform (pcDNA3-DEST-human TAp73 $\alpha-\varepsilon$-myc- $6 \times$ His) were co-transfected into HeLa cells. At $48 \mathrm{~h}$ after transfection, HeLa cells were incubated with $500 \mathrm{nM}$ 17-AAG for $24 \mathrm{~h}(+17-\mathrm{AAG})$, and protein extracts were prepared. Proteins in the total cell lysate $(\mathrm{T})$ and precipitate $(\mathrm{P})$ obtained using Ni-NTA agarose purification were detected with anti-TAp73 specific antibody. The volume of the total cell lysate was $6 \%$ of that of the starting material. (e) (Top panel) Overexpression of $\Delta$ Np73 isoforms. HeLa cells were transfected with either empty vector or expression plasmids encoding each isoform of $\Delta$ Np73 (pcDNA3-DEST-human $\Delta$ Np $73 \alpha-\varepsilon-$ myc- $6 \times$ His), as indicated. Western blot analysis of total HeLa cell lysates collected $48 \mathrm{~h}$ after transfection was performed. GAPDH protein was the loading control. (Bottom panel) Overexpression of $\Delta \mathrm{Np} 73 \alpha, \beta$, and $\gamma$, but not $\varepsilon$ suppressed the CIMD phenotype as the dominant-negative mutant. The histogram summarizes results of the TUNEL assay of cells partially depleted of BUB1. At $48 \mathrm{~h}$ after HeLa cells were co-transfected with the plasmid pEGFP-N1 as transfection marker, plus with overexpression vector of each $\triangle N p 73$ isoform (as shown in top panel) and BUB1 siRNA (partial), they were incubated with 17-AAG ( $+17 \mathrm{AAG}, 500 \mathrm{nM}$ ) for $24 \mathrm{~h}$ at $37^{\circ} \mathrm{C}$. Cells transfected with Luc siRNA and/or vector were used as control. TUNEL staining was performed as described in Figure $3 \mathrm{c}$ and $d$. The number of TUNEL-positive cells among GFP-positive mitotic cells in each of two independent experiments was counted, and the mean percentages ( \pm S.D.) (i.e., the number of mitotic TUNEL-positive cells per total GFP-positive mitotic cells) are shown. $\left({ }^{*}\right) P<0.01$ compared with vector + BUB1 siRNA (partial) plus 17-AAG (Student's $t$-test) 


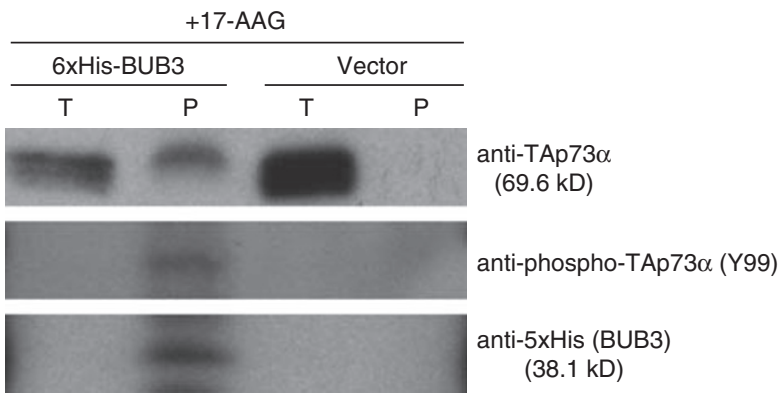

b
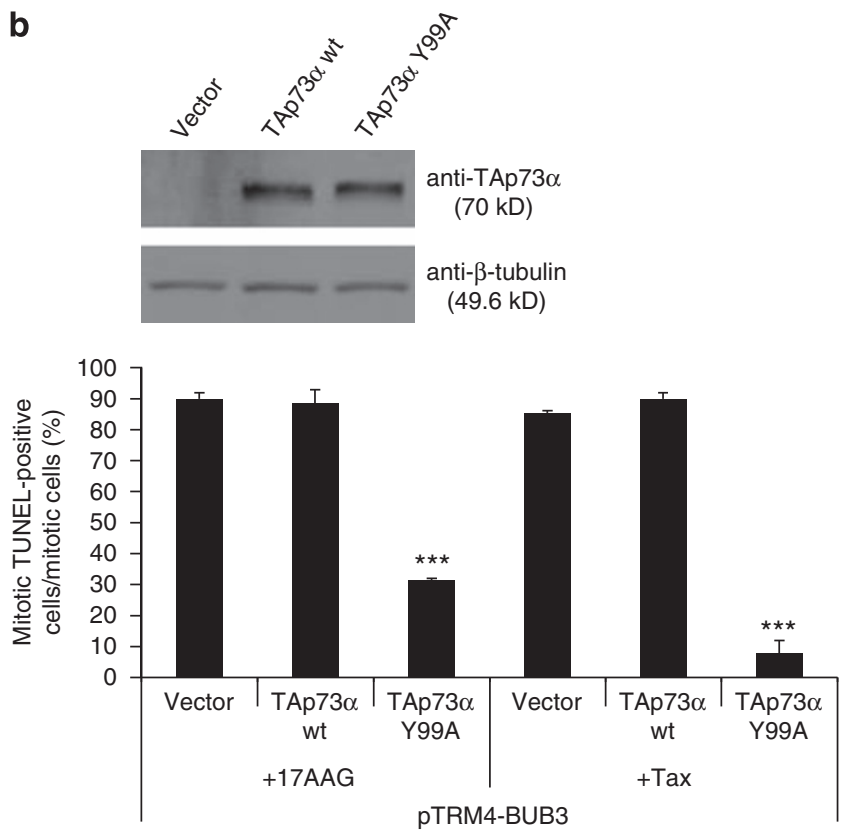
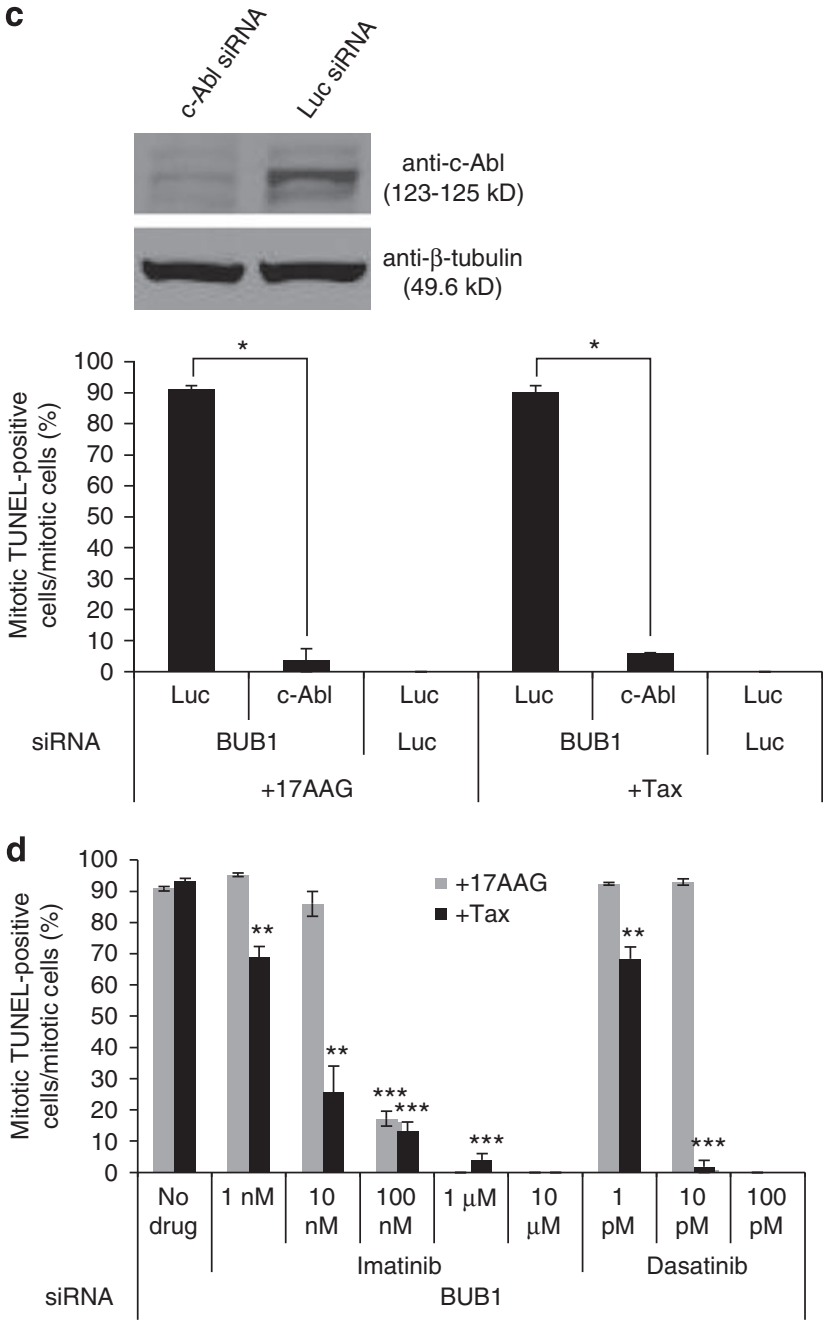

Figure 5 Tyrosine 99 phosphorylation on TAp73 $\alpha$ by c-Abl tyrosine kinase is required for CIMD activation. (a) Tyrosine 99-phosphorylated TAp73 $\alpha$ interacts with BUB3. Cell culture, transfection, 17-AAG treatment, and protein extraction were performed as described in Figure 3a. Proteins in the total cell lysate $(T)$ and precipitate $(P)$ obtained using Ni-NTA agarose purification were detected both with p73 $\alpha$ antibody (top and bottom panels, as shown in Figure 3a) and with phospho-p73 $\alpha$ (Y99) antibody (middle panel). The volume of the total cell lysate was $12 \%$ of that of the starting material. (b) Overexpression of the nonphosphorylation mutant TAp73 $\alpha$-Y99A can suppress CIMD. (Top panel) HeLa cells that expressed pcDNA3-human TAp73 $\alpha$ WT, Y99A mutant, or vector only were immunoblotted with anti-p73 $\alpha$ antibody. At $48 \mathrm{~h}$ after transfection, protein extracts were prepared. $\beta$-Tubulin protein was the loading control. (Bottom panel) HeLa cells were co-transfected with plasmid pEGFP-N1, as a transfection marker, plus pTRM4-human BUB3 + pcDNA3-human TAp73 $\alpha$ WT, Y99A mutant, or vector only. At $48 \mathrm{~h}$ after transfection, cells were treated with 17-AAG or Taxol and incubated for another $24 \mathrm{~h}$. TUNEL staining was performed as described in Figure $3 \mathrm{c}$ and d. Samples were examined under a fluorescent microscope, and more than $100 \mathrm{GFP}$-positive mitotic cells in each of three independent experiments were counted, and the mean percentages ( \pm S.D.) (i.e., the number of mitotic TUNEL-positive cells per total GFPpositive mitotic cells) are shown. $\left(^{* \star *}\right) P<0.0001$ compared with pcDNA3 vector + pTRM4-human BUB3 plus 17-AAG or Taxol (Student's $t$-test). (c) Depletion of c-Abl abolishes CIMD. (Top panel) Western blot analysis of total HeLa cell lysates collected $48 \mathrm{~h}$ after transfection with siRNA duplexes directed against c-Abl shows partial depletion of protein. Results from control experiments in which Luc siRNA was transfected into cells are shown. $\beta$-Tubulin protein was the loading control. (Bottom panel) Partial depletion of c-Abl suppresses CIMD induced by BUB1 partial depletion. The histogram summarizes the results of the TUNEL assay of cells partially depleted of BUB1. At $48 \mathrm{~h}$ after HeLa cells were transfected with BUB1 (partial) + c-Abl siRNA or BUB1 (partial) + Luc siRNA, they were incubated with 17-AAG ( + 17AAG, 500 nM) or Taxol ( + Taxol, $10 \mathrm{nM}$ ) for $24 \mathrm{~h}$ at $37^{\circ} \mathrm{C}$. TUNEL staining was performed as described in Figure $3 \mathrm{c}$ and d, and CIMD induced by BUB1 partial depletion, as reported previously, ${ }^{32}$ was significantly suppressed by partial depletion of c-Abl. The number of TUNEL-positive cells among more than 100 mitotic cells in each of three independent experiments was counted, and the mean percentages ( \pm S.D.) (i.e., the number of mitotic TUNEL-positive cells per total mitotic cells) are shown. $\left({ }^{*}\right) P<0.01$ compared with BUB1 (partial) + Luc siRNA plus 17-AAG or Taxol (Student's t-test). (d) c-Abl inhibitors (imatinib and dasatinib) suppress CIMD induced by BUB1 partial depletion plus 17-AAG or Taxol treatment. Samples were examined under a fluorescent microscope, and more than 100 cells in each of three independent experiments were counted. Gray and black bars represent the mean percentages ( \pm S.D.) of mitotic TUNEL-positive cells treated with 17-AAG $(500 \mathrm{nM})$ and Taxol $(10 \mathrm{nM})$, respectively. Cell culture, transfection, 17AAG or Taxol treatment, and TUNEL staining were performed as described in Figure $3 \mathrm{c}$ and d. Various concentrations of c-Abl inhibitors, imatinib (1 nM-10 $\mu \mathrm{M})$ or dasatinib $(1-100 \mathrm{pM})$, were used together with 17-AAG or Taxol treatment, and the c-Abl inhibitors remained in the medium during 17-AAG or Taxol treatment. ( $\left.{ }^{* \star *}\right) P<0.0001$ and $\left.{ }^{* \star}\right) P<0.001$ compared with BUB1 siRNA (partial) with 17-AAG or Taxol treatment plus no c-Abl inhibitors (Student's $t$-test)

$2 \mathrm{mM}$ L-glutamine (Invitrogen), $0.1 \mathrm{mM}$ MEM nonessential amino acids (Invitrogen), $55 \mu \mathrm{M} \beta$-mercaptoethanol (Invitrogen), and $10 \mu \mathrm{g} / \mathrm{ml}$ gentamicin (Invitrogen). Cells were grown at $37^{\circ} \mathrm{C}$ under $5 \% \mathrm{CO}_{2}$ in a humidified incubator. Cells were transfected with annealed double-stranded siRNA or mammalian expression plasmids by using Lipofectamine 2000 (Invitrogen), Lipofectamine LTX (Invitrogen), or Fugene 6 (Roche, Indianapolis, IN, USA). HeLa Tet-Off cells were transiently transfected with 
a
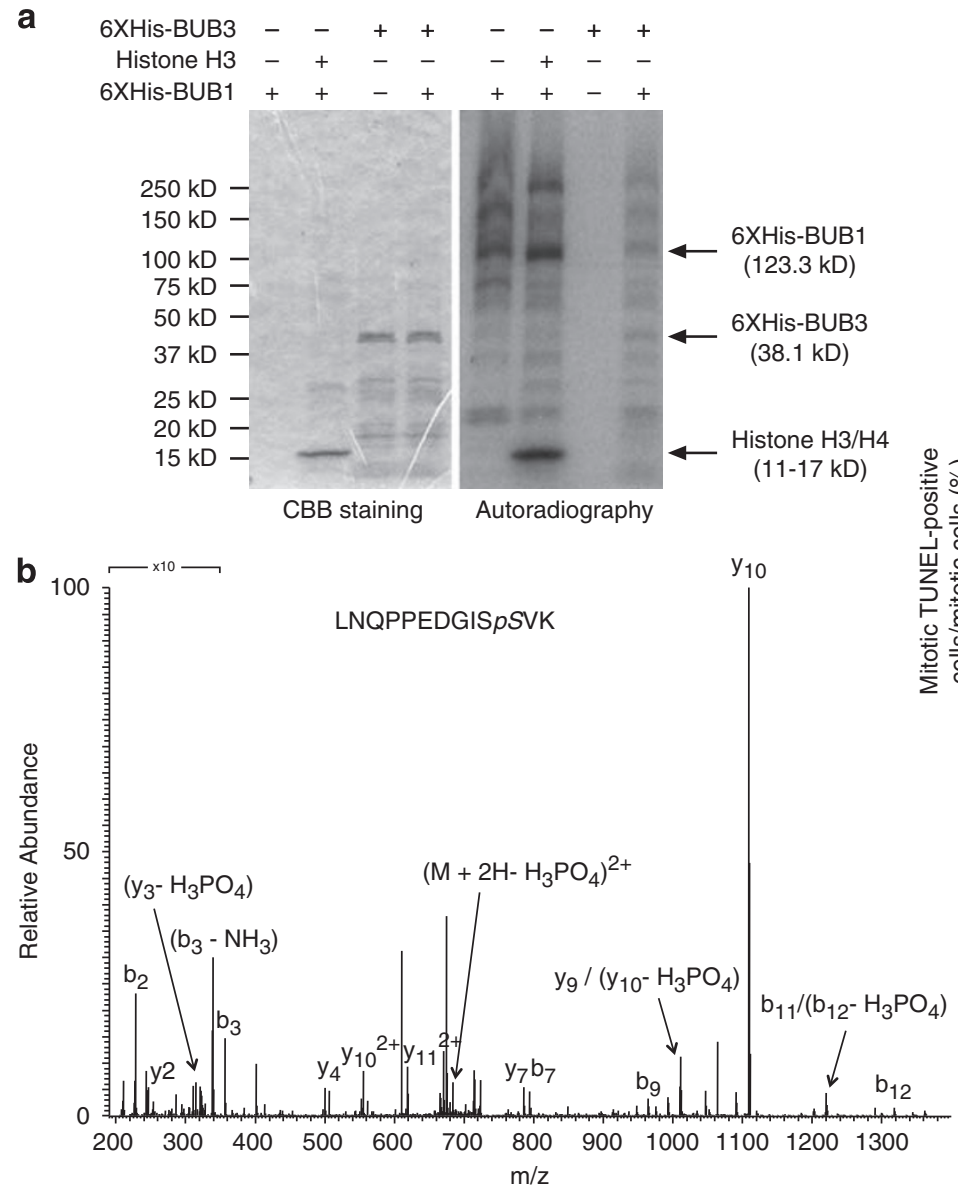

C

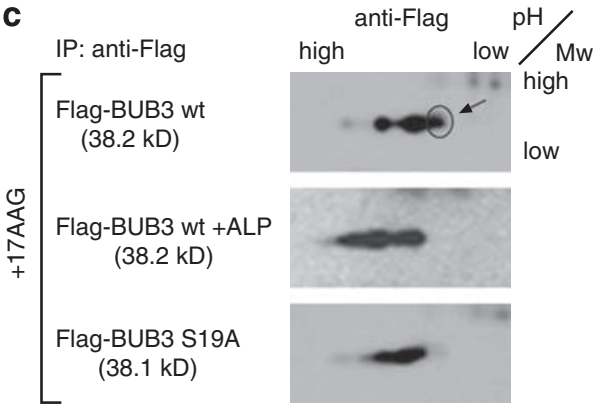

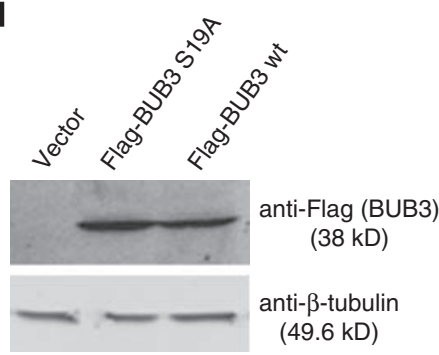

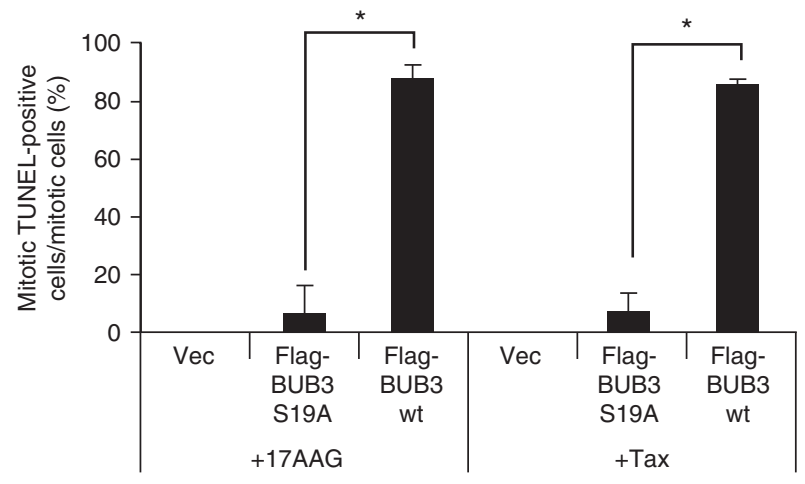

e Flag-BUB3 Flag-BUB3

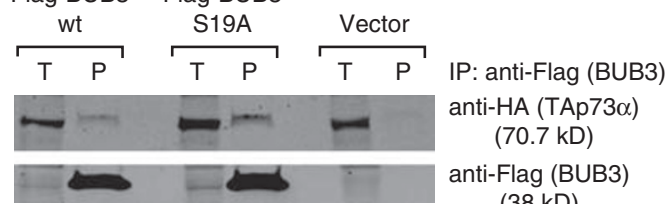

$(38 \mathrm{kD})$

Figure 6 Serine 19 phosphorylation on BUB3 by BUB1 kinase is required for CIMD activation. (a) BUB3 is phosphorylated by BUB1 in vitro. $6 \times$ His-BUB1 was expressed in insect cells and $6 \times$ His-BUB3 was expressed in $E$. coli, and both were affinity purified on a nickel column. Histone $\mathrm{H} 3 / \mathrm{H} 4$ or $6 \times$ His-human BUB3 was incubated with or without $6 \times$ His-human Bub1. Samples were electrophoresed on an SDS-PAGE gel, stained with CBB, and dried. The incorporation of phosphate was detected by autoradiography. (b) Serine 19 on BUB3 is a phosphorylation site for BUB1 in vitro. Mass spectrometric analysis was performed on samples from the in vitro kinase assay, as shown in (a). Mass spectrometric data showing the phosphorylation of S19, identified from the tryptic peptide LNQPPEDGISpSVK, are presented. For clarity, some neutral losses in the mass spectrum are not labeled. (c) BUB3 is phosphorylated on serine 19 in vivo. Two-dimensional gel electrophoresis was performed using human BUB3 WT and S19A mutant in vivo. Plasmid pcDNA3-DEST-Flag-human BUB3 WT or S19A mutant was transfected into HeLa cells. At $48 \mathrm{~h}$ after transfection, HeLa cells were incubated with $500 \mathrm{nM}$ 17-AAG for $24 \mathrm{~h}$ ( $+17-$ $A A G)$, and protein extracts were prepared. Immunoprecipitates obtained using an anti-Flag antibody were treated or not treated with alkaline phosphatase $(+A L P, 0.2$ unit $\mu l)$ as control, and analyzed by two-dimensional gel electrophoresis. An anti-Flag antibody was used to detect Flag-BUB3 WT and S19A mutant on the immunoblots. Alkaline phosphatase treatment of immunopurified BUB3 reduced the intensity of the signal of the dot at the far right (top (arrow and circle) and middle panels) and the corresponding dot was absent in an unphosphorylated mutant BUB3-S19A (bottom panel). (d) Overexpression of the nonphosphorylation mutant BUB3-S19A can suppress CIMD. (Top panel) HeLa cells that expressed pcDNA3-DEST-Flag-human BUB3 WT, S19A mutant, or vector only were immunoblotted with anti-Flag antibody. At $48 \mathrm{~h}$ after transfection, protein extracts were prepared. $\beta$-Tubulin protein was the loading control. (Bottom panel) HeLa cells were co-transfected with pcDNA3-DEST-Flag-human BUB3 WT, S19A mutant, or vector only. At 48 $\mathrm{h}$ after transfection, cells were treated with 17-AAG or Taxol and incubated for another $24 \mathrm{~h}$. TUNEL staining was performed with anti-Flag immunostaining. Samples were examined under a fluorescent microscope, and Flag-positive mitotic cells in each of two independent experiments were counted. The mean percentages ( \pm S.D.) (i.e., the number of mitotic TUNEL-positive cells per total Flag-positive mitotic cells) are shown. (*) $P<0.01$ compared with Flag-BUB3 WT plus 17-AAG or Taxol (Student's t-test). (e) Immunoblot analysis of BUB3 immunoprecipitates. Plasmids pcDNA3-Flag-DEST-human BUB3 WT, S19A mutant or vector only, and pcDNA3-HA-human TAp73 $\alpha$ were co-transfected into HeLa cells. At $48 \mathrm{~h}$ after transfection, HeLa cells were incubated with $500 \mathrm{nM} 17-\mathrm{AAG}$ for $24 \mathrm{~h}(+17-\mathrm{AAG})$, and protein extracts were prepared. Proteins in the total cell lysate (T) and precipitate $(\mathrm{P})$ obtained using ANTI-FLAG M2 Affinity Gel (Sigma) were detected with anti-HA antibody. The volume of the total cell lysate was $2 \%$ of that of the starting material 


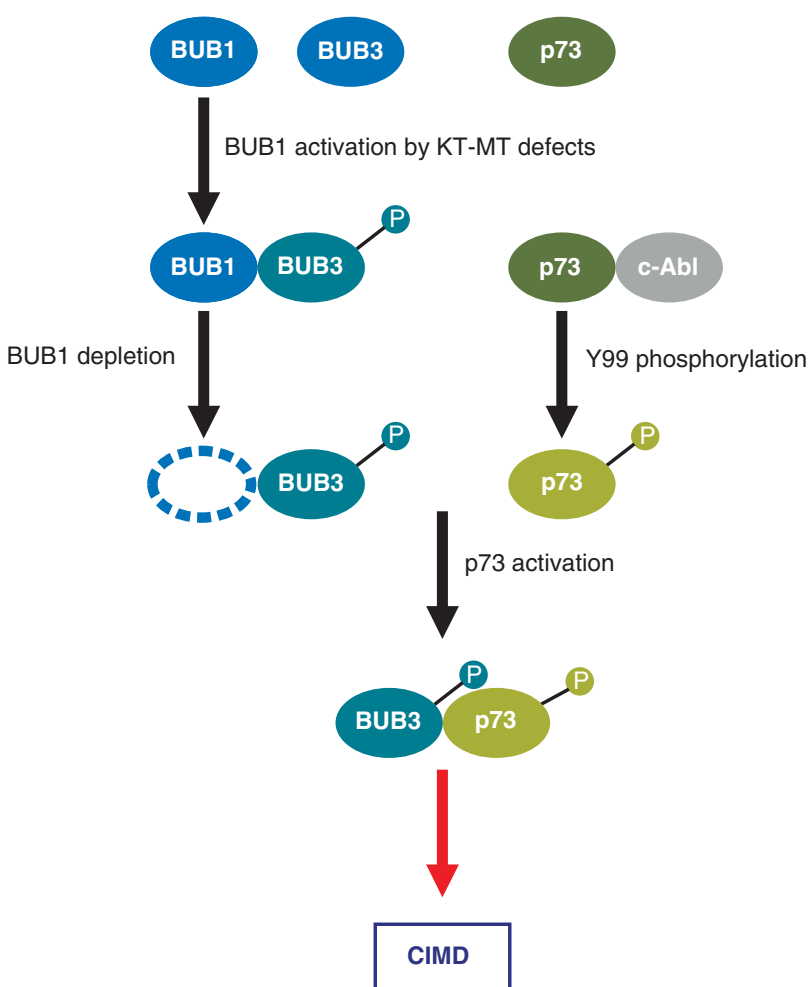

Figure 7 Model describing the molecular mechanism of CIMD induction. KT-MT defects activate BUB1. The activated BUB1 binds to BUB3 and phosphorylates it on serine 19 (S19). The phosphorylated BUB3 can not bind to p73 while it is bound to BUB1. However, p73 has to be phosphorylated on tyrosine 99 (Y99) by c-Abl kinase to interact with phosphorylated and BUB1-released BUB3. When BUB1 is partially depleted or BUB3 is overexpressed under the KT-MT defect, BUB3 can bind to $p 73$ to activate its transcriptional activity and then induce CIMD

pTRM4 overexpression vector, the transcription of which was regulated by the TRE promoter, and cultured in the absence of tetracycline/doxycycline.

Colony outgrowth assay. Colony outgrowth assay was performed as described previously, ${ }^{75-77}$ but with a minor modification. HeLa cells were transfected with siRNAs using Lipofectamine 2000. At $24 \mathrm{~h}$ after transfection, cells were incubated with $100 \mathrm{nM} 17-\mathrm{AAG}$ or $1.5 \mathrm{nM}$ Taxol for 2 days, and the drug was removed by washing while retaining the mitotic cells. Cells including mitotic cells that were recovered from the supematant, $n=500$ or 2000, were spread in one well of a six-well cluster (Corning Costar, Acton, MA, USA) and incubated for approximately 20 days or 12-14 days, respectively, to allow colony formation. Colonies stained with Giemsa solution (HEMA-QUIK stain solution, Fisher Scientific, Hampton, NH, USA) were counted. Viability (\%) was normalized and the percentage of surviving colonies of untreated cells transfected with control luciferase (Luc) siRNA was arbitrarily set to 100.

Immunoblotting. Immunoblotting was performed as previously described. ${ }^{78,79}$ Alternatively, the Odyssey Infrared Imaging System (LI-COR Biosciences, Lincoln, NE, USA) was used, especially for co-immunoblotting. Cells were added to lysis buffer $A{ }^{80}$ and the mixture was frozen in liquid nitrogen, thawed, and sonicated. Before electrophoresis, cell lysates were mixed with an equal volume of $2 \times$ SDS sample buffer.

Immunofluorescence. Indirect immunofluorescent staining was performed using previously described methods, ${ }^{81,82}$ but with the following modifications: HeLa cells were grown for $48 \mathrm{~h}$ on coverslip slides after siRNA and/or overexpression plasmid vector transfection (seeding approximately $1.8 \times 10^{5}$ cells, and cells were grown for $18 \mathrm{~h}$ before transfection). Asynchronous populations of HeLa cells were fixed in $4 \%$ paraformaldehyde in phosphate-buffered saline (PBS) at $4{ }^{\circ} \mathrm{C}$ for $30 \mathrm{~min}$ and then treated with $0.5 \%$ Triton $\mathrm{X}-100$ in $\mathrm{KB}(10 \mathrm{mM}$ Tris- $\mathrm{HCl}(\mathrm{pH} 7.5), 150 \mathrm{mM}$ $\mathrm{NaCl}, 0.5 \%$ bovine serum albumin) at room temperature for $30 \mathrm{~min}$. Cells were then incubated with a specific primary antibody for $1 \mathrm{~h}$ at $37^{\circ} \mathrm{C}$. After the cells were washed once with $\mathrm{KB}$, they were incubated with the fluorescent secondary antibodies fluorescein isothiocyanate-conjugated AffiniPure IgG, Texas Redconjugated AffiniPure IgG (Jackson ImmunoResearch Laboratories, West Grove, PA, USA), Alexa Fluor 488 (Molecular Probes, Eugene, OR, USA), or co-incubated with the TUNEL reaction mixture (see TUNEL assay) for $1 \mathrm{~h}$ at $37^{\circ} \mathrm{C}$. Slides were washed once with KB and then incubated in KB containing $0.1 \mu \mathrm{g} / \mathrm{ml}$ DAPI (Sigma, St. Louis, MO, USA). Cells were observed through a Leica DM IRE2 motorized fluorescence microscope equipped with an HCX PL APO $\times 63$ oil immersion lens (Leica, Bannockburn, IL, USA), a Leica EL6000 compact light source (Leica), and an ORCA-ER high-resolution digital charge-coupled device (CCD) camera (Hamamatsu, Bridgewater, NJ, USA). Image acquisition and processing were performed using Openlab version 5 scientific imaging software (Improvision, Lexington, MA, USA).

TUNEL assay. At $48 \mathrm{~h}$ after siRNA and/or overexpression plasmid vector transfection, HeLa cells were incubated with $500 \mathrm{nM}$ 17-AAG (AG Scientific, San Diego, CA, USA) for $24 \mathrm{~h}$. Cells were fixed with $4 \%$ paraformaldehyde in PBS (pH 7.4), and TUNEL assay was performed using an in situ cell death detection system that contained tetra-methyl-rhodamine (TMR) red (Roche).

Caspase assay. HeLa cells were transfected with siRNA, and $48 \mathrm{~h}$ later they were incubated in $500 \mathrm{nM} 17-\mathrm{AAG}$ for $24 \mathrm{~h}$. Fluorochrome inhibitor of caspases (FLICA) assay was performed using the carboxyfluorescein FLICA (poly-Caspases FLICA (SR-VAD-FMK), caspase 2 FLICA (FAM-VDVAD-FMK), caspase 10 FLICA (FAM-AEVD-FMK), or caspase 13 FLICA (FAM-LEED-FMK)) apoptosis detection system (Immunochemistry Technologies, Bloomington, MN, USA).

Immunoprecipitation assay. We used a previously described method for immunoprecipitation assay, ${ }^{83}$ but with the following modifications: extracts of HeLa cells cultured in 100-mm dishes were obtained by lysing cells in cold buffer B1 $(40 \mathrm{mM}$ Tris- $\mathrm{HCl}(\mathrm{pH} 7.5), 300 \mathrm{mM} \mathrm{NaCl}, 0.5 \%$ Triton X-100, and one tablet of EDTA-free protease inhibitor cocktail (Roche) per $10 \mathrm{ml}$ ) or buffer B2 $(50 \mathrm{mM}$ HEPES-KOH (pH 7.2), $120 \mathrm{mM} \mathrm{NaCl}, 0.1 \%$ NP-40, $1 \mathrm{mM}$ EDTA, $60 \mathrm{mM}$ $\beta$-glycerolphosphate, $0.1 \mathrm{mM} \mathrm{NaF}, 0.1 \mathrm{mM} \mathrm{Na}_{3} \mathrm{VO}_{4}, 1 \mathrm{mM} \mathrm{PMSF}$, and one tablet of EDTA-free protease inhibitor cocktail (Roche) per $10 \mathrm{ml}$ ), and the mixture was frozen in liquid nitrogen, thawed, and sonicated on ice. Approximately $1-4 \mathrm{mg}$ of protein lysates were used per immunoprecipitation experiment. After centrifuging $\left(15000 \times g\right.$ for $20 \mathrm{~min}$ at $4^{\circ} \mathrm{C}$ ) the lysates, $6 \times$ His-tagged protein was precipitated using $25 \mu \mathrm{l}$ of Ni-NTA agarose (QIAGEN, Valencia, CA, USA) at $4{ }^{\circ} \mathrm{C}$ for $2 \mathrm{~h}$ to overnight. To precipitate HA-tagged protein, $4 \mu \mathrm{g}$ of anti-HA antibody (Roche) was preincubated with $25 \mu \mathrm{l}$ of protein A-Sepharose (Amersham Biosciences, Piscataway, NJ, USA) at $4{ }^{\circ} \mathrm{C}$ for $1 \mathrm{~h}$ to overnight, and then the HA-tagged protein in the supernatant was precipitated with anti-HA antibody-linked protein A Sepharose at $4{ }^{\circ} \mathrm{C}$ for $2 \mathrm{~h}$ to overnight. Flag-tagged protein was precipitated using $25 \mu \mathrm{l}$ of ANTI-FLAG M2 Affinity Gel (Sigma) at $4{ }^{\circ} \mathrm{C}$ for $2 \mathrm{~h}$ to overnight. Myc-tagged protein was precipitated using $25 \mu \mathrm{l}$ of C-Myc Monoclonal Ab-Agarose Beads (Clontech) at $4{ }^{\circ} \mathrm{C}$ for $2 \mathrm{~h}$ to overnight. Immunoprecipitates were washed six times with buffer $\mathrm{B} 1$ or $\mathrm{B} 2$, and the precipitated protein was eluted in buffer $\mathrm{C}\left(50 \mathrm{mM} \mathrm{NaH}_{2} \mathrm{PO}_{4}(\mathrm{pH} 8.0)\right.$, $300 \mathrm{mM} \mathrm{NaCl}, 250 \mathrm{mM}$ imidazole) or in SDS sample buffer $(50 \mathrm{mM}$ Tris- $\mathrm{HCl}$ (pH 6.8), $2 \%$ SDS, $0.1 \%$ bromophenol blue, and $10 \%$ glycerol).

RT-PCR. Total RNA from HeLa cells was extracted using TRIzol reagent (Invitrogen) according to the manufacturer's instructions. To examine siRNA silencing activity, CDNA was synthesized from RNA $(500 \mathrm{ng})$ and DNA amplification was performed using the One Step RT-PCR kit (QIAGEN). For amplification of gene-specific fragments, RT-PCR was performed under the following conditions: reverse transcription at $50^{\circ} \mathrm{C}$ for $30 \mathrm{~min}, 30$ cycles: $94^{\circ} \mathrm{C}$ for $60 \mathrm{~s}, 50^{\circ} \mathrm{C}$ for $60 \mathrm{~s}$, and $72{ }^{\circ} \mathrm{C}$ for $60 \mathrm{~s}$, and final extension at $72{ }^{\circ} \mathrm{C}$ for $10 \mathrm{~min}$.

In vitro BUB1 kinase assay. The $6 \times$ His-human BUB3 or $6 \times$ His-human BUB1 protein was expressed in Escherichia coli or sf9 cells, respectively, purified with Ni-NTA agarose (QIAGEN), and dialyzed with dialysis buffer $(50 \mathrm{mM}$ Tris- $\mathrm{HCl}$ (pH 7.5), $150 \mathrm{mM} \mathrm{NaCl}, 10 \mathrm{mM} \mathrm{MgCl}_{2}, 0.1 \%$ Triton X-100, $1 \mathrm{mM} \mathrm{DTT}$ ). Histone $\mathrm{H} 3 / \mathrm{H} 4$ (US Biological, Swampscott, MA, USA) or $6 \times$ His-human BUB3 was incubated in the reaction buffer ( $50 \mathrm{mM}$ Tris- $\mathrm{HCl}(\mathrm{pH} 7.5), 10 \mathrm{mM} \mathrm{MgCl}_{2}, 10 \mu \mathrm{M}$ ATP) with or without $6 \times$ His-human BUB1 at $30^{\circ} \mathrm{C}$ for $1 \mathrm{~h}$ in the presence of $2 \mu \mathrm{Ci}$ of $\left[\gamma^{32} \mathrm{P}\right]-$ ATP. Phosphorlmager (Molecular Dynamics, Sunnyvale, CA, USA) was used to detect phosphorylation. 
Mass spectrometry. The BUB3 region from the gel was reduced by $10 \mathrm{mM}$ dithiothreitol, alkylated with $25 \mathrm{mM}$ iodoacetamide, and digested with $0.2 \mu \mathrm{g}$ trypsin. Mass spectrometric analysis was performed on an LTQ Linear Ion Trap Mass Spectrometer from Thermo Electron (San Jose, CA, USA) using electrospray ionization (ESI). Tryptic peptides were introduced into the instrument by gradient elution (by increasing the concentration of acetonitrile), using reverse phase (C18) ultra-high pressure liquid chromatography on the nanoAcquity (Waters, MA, USA). Waters BEHC18 with an I.D. of $75 \mu \mathrm{m}$ and a particle size of $1.7 \mu \mathrm{m}$ was used. Data on peptide mass (MS) spectra, followed by fragmentation of the 10 most intense ions in the MS, were acquired. Database searches were performed on these MS/MS data, using the Mascot search engine on the Swissprot database. The parameters used in the search were 1.5 and $0.7 \mathrm{Da}$ for precursor and fragment ion mass tolerances, respectively, and static modification of carbamidomethyl on C. Oxidation of $M$ and phosphorylation on STY were used as variable modifications. Phosphopeptides identified from the search were manually confirmed.

Two-dimensional gel electrophoresis. We used a previously described method for the two-dimensional gel electrophoresis, ${ }^{84}$ but with the following modifications: Flag-tagged BUB3 was immunoprecipitated from HeLa cell lysates using an anti-Flag antibody. Isoelectric focusing was performed with $17-\mathrm{cm}$ immobilized pH 3-10 gradient strips (Bio-Rad, Hercules, CA, USA) as per the manufacturer's instructions. Gel electrophoresis was performed in a Bio-Rad PROTEAN Plus Dodeca cell. After two-dimensional gel electrophoresis, proteins were transferred on to an Immobilon-FL polyvinylidene difluoride membrane (Millipore, Danvers, MA, USA) and immunoblotted using anti-Flag antibodies.

\section{Conflict of interest}

The authors declare no conflict of interest.

Acknowledgements. We thank DR Green, $Y$ Fujii, and $P$ Bansal for their helpful comments; $\mathrm{P}$ Houghton and $\mathrm{H}$ Cam for stimulating conversation and advice; R Abdulle, P Sprouse, S Watanabe, Y Sakuraba, Y Fujii, G Stocco, G Neale, A Inoue, R Chitta, $X$ Ding, and V Pagala for their technical assistance; WG Kaelin, $\mathrm{Jr}$ and $\mathrm{P}$ Houghton for their generous gifts of reagents; and V Shanker for editing this paper. This study was supported by the Cancer Center Support Grant CA21765 from the National Cancer Institute, by NIH grant GM68418, by American Cancer Society Research Grant RSG-07-144-01-CCG, and by the American Lebanese Syrian Associated Charities (ALSAC).

1. Williams BR, Prabhu VR, Hunter KE, Glazier CM, Whittaker CA, Housman DE et al. Aneuploidy affects proliferation and spontaneous immortalization in mammalian cells. Science 2008; 322: 703-709.

2. Hernando E. Cancer. Aneuploidy advantages? Science 2008; 322: 692-693.

3. Weaver BA, Cleveland DW. The aneuploidy paradox in cell growth and tumorigenesis Cancer Cell 2008; 14: 431-433.

4. Weaver BA, Cleveland DW. Does aneuploidy cause cancer? Curr Opin Cell Biol 2006; 18 658-667.

5. Weaver BA, Silk AD, Montagna C, Verdier-Pinard P, Cleveland DW. Aneuploidy acts both oncogenically and as a tumor suppressor. Cancer Cell 2007; 11: 25-36.

6. Musacchio A, Salmon ED. The spindle-assembly checkpoint in space and time. Nat Rev Mol Cell Biol 2007; 8: 379-393.

7. Rieder CL, Maiato H. Stuck in division or passing through: what happens when cells cannot satisfy the spindle assembly checkpoint. Dev Cell 2004; 7: 637-651.

8. Li R, Murray AW. Feedback control of mitosis in budding yeast. Cell 1991; 66: 519-531.

9. Hoyt MA, Totis L, Roberts BT. S. cerevisiae genes required for cell cycle arrest in response to loss of microtubule function. Cell 1991; 66: 507-517.

10. Wells WA, Murray AW. Aberrantly segregating centromeres activate the spindle assembly checkpoint in budding yeast. J Cell Biol 1996; 133: 75-84.

11. Kitagawa K, Hieter P. Evolutionary conservation between budding yeast and human kinetochores. Nat Rev Mol Cell Biol 2001; 2: 678-687.

12. Kops GJ, Weaver BA, Cleveland DW. On the road to cancer: aneuploidy and the mitotic checkpoint. Nat Rev Cancer 2005; 5: 773-785.

13. Kops GJ. The kinetochore and spindle checkpoint in mammals. Front Biosci 2008; 13 3606-3620

14. Cahill DP, Lengauer C, Yu J, Riggins GJ, Willson JK, Markowitz SD et al. Mutations of mitotic checkpoint genes in human cancers. Nature 1998; 392: 300-303.

15. Ohshima K, Haraoka S, Yoshioka S, Hamasaki M, Fujiki T, Suzumiya J et al. Mutation analysis of mitotic checkpoint genes ( $h B U B 1$ and hBUBR1) and microsatellite instability in adult T-cell leukemia/lymphoma. Cancer Lett 2000; 158: 141-150.
16. Ru HY, Chen RL, Lu WC, Chen JH. hBUB1 defects in leukemia and lymphoma cells. Oncogene 2002; 21: 4673-4679.

17. Tsukasaki K, Miller CW, Greenspun E, Eshaghian S, Kawabata H, Fujimoto T et al. Mutations in the mitotic check point gene, MAD1L1, in human cancers. Oncogene 2001; 20: $3301-3305$

18. Saeki A, Tamura S, Ito $N$, Kiso $S$, Matsuda $Y$, Yabuuchi I et al. Frequent impairment of the spindle assembly checkpoint in hepatocellular carcinoma. Cancer 2002; 94: 2047-2054.

19. Shigeishi H, Oue N, Kuniyasu H, Wakikawa A, Yokozaki H, Ishikawa T et al. Expression of Bub1 gene correlates with tumor proliferating activity in human gastric carcinomas. Pathobiology 2001; 69: 24-29.

20. Wang $X$, Jin DY, Ng RW, Feng $H$, Wong YC, Cheung AL et al. Significance of MAD2 expression to mitotic checkpoint control in ovarian cancer cells. Cancer Res 2002; 62: 1662-1668.

21. Yoon DS, Wersto RP, Zhou W, Chrest FJ, Garrett ES, Kwon TK et al. Variable levels of chromosomal instability and mitotic spindle checkpoint defects in breast cancer. $\mathrm{Am} \mathrm{J}$ Pathol 2002; 161: 391-397.

22. Michel LS, Liberal V, Chatterjee A, Kirchwegger R, Pasche B, Gerald W et al. MAD2 haploinsufficiency causes premature anaphase and chromosome instability in mammalian cells. Nature 2001; 409: 355-359.

23. Babu JR, Jeganathan KB, Baker DJ, Wu X, Kang-Decker N, van Deursen JM. Rae1 is an essential mitotic checkpoint regulator that cooperates with Bub3 to prevent chromosome missegregation. J Cell Biol 2003; 160: 341-353.

24. Dai W, Wang Q, Liu T, Swamy M, Fang Y, Xie $S$ et al. Slippage of mitotic arrest and enhanced tumor development in mice with BubR1 haploinsufficiency. Cancer Res 2004; 64: $440-445$.

25. Mollinedo F, Gajate C. Microtubules, microtubule-interfering agents and apoptosis. Apoptosis 2003; 8: 413-450

26. Blank M, Lerenthal $Y$, Mittelman L, Shiloh $Y$. Condensin I recruitment and uneven chromatin condensation precede mitotic cell death in response to DNA damage. J Cell Biol 2006; 174: 195-206.

27. Burns TF, Fei P, Scata KA, Dicker DT, El-Deiry WS. Silencing of the novel p53 target gene Snk/Plk2 leads to mitotic catastrophe in paclitaxel (taxol)-exposed cells. Mol Cell Biol 2003; 23: 5556-5571.

28. DeLuca JG, Moree B, Hickey JM, Kilmartin JV, Salmon ED. hNuf2 inhibition blocks stable kinetochore-microtubule attachment and induces mitotic cell death in HeLa cells. J Cell Biol 2002; 159: 549-555.

29. Woods CM, Zhu J, McQueney PA, Bollag D, Lazarides E. Taxol-induced mitotic block triggers rapid onset of a p53-independent apoptotic pathway. Mol Med 1995; 1 : 506-526.

30. Yang Z, Guo J, Chen Q, Ding C, Du J, Zhu X. Silencing mitosin induces misaligned chromosomes, premature chromosome decondensation before anaphase onset, and mitotic cell death. Mol Cell Biol 2005; 25: 4062-4074.

31. Kitagawa K, Niikura Y. Caspase-independent mitotic death (CIMD). Cell Cycle 2008; 7: 1001-1005.

32. Niikura $Y$, Dixit A, Scott R, Perkins G, Kitagawa K. BUB1 mediation of caspaseindependent mitotic death determines cell fate. J Cell Biol 2007; 178: 283-296.

33. Cregan SP, Dawson VL, Slack RS. Role of AIF in caspase-dependent and caspaseindependent cell death. Oncogene 2004; 23: 2785-2796.

34. Masud A, Mohapatra A, Lakhani SA, Ferrandino A, Hakem R, Flavell RA. Endoplasmic reticulum stress-induced death of mouse embryonic fibroblasts requires the intrinsic pathway of apoptosis. J Biol Chem 2007; 282: 14132-14139.

35. Kops GJ, Foltz DR, Cleveland DW. Lethality to human cancer cells through massive chromosome loss by inhibition of the mitotic checkpoint. Proc Natl Acad Sci USA 2004; 101: 8699-8704

36. Taylor SS, $\mathrm{Ha} \mathrm{E}, \mathrm{McKeon} \mathrm{F}$. The human homologue of Bub3 is required for kinetochore localization of Bub1 and a Mad3/Bub1-related protein kinase. J Cell Biol 1998: 142: 1-11.

37. Tang Z, Shu H, Oncel D, Chen S, Yu H. Phosphorylation of Cdc20 by Bub1 provides a catalytic mechanism for APC/C inhibition by the spindle checkpoint. Mol Cell 2004; 16 : 387-397.

38. De Laurenzi V, Costanzo A, Barcaroli D, Terrinoni A, Falco M, Annicchiarico-Petruzzelli M et al. Two new p73 splice variants, gamma and delta, with different transcriptional activity. J Exp Med 1998; 188: 1763-1768.

39. De Laurenzi VD, Catani MV, Terrinoni A, Corazzari M, Melino G, Costanzo A et al. Additional complexity in p73: induction by mitogens in lymphoid cells and identification of two new splicing variants epsilon and zeta. Cell Death Differ 1999; 6: 389-390.

40. Ishimoto O, Kawahara C, Enjo K, Obinata M, Nukiwa T, Ikawa S. Possible oncogenic potential of DeltaNp73: a newly identified isoform of human p73. Cancer Res 2002; 62: 636-641

41. Kaghad M, Bonnet $\mathrm{H}$, Yang A, Creancier $\mathrm{L}$, Biscan JC, Valent $\mathrm{A}$ et al. Monoallelically expressed gene related to $p 53$ at $1 p 36$, a region frequently deleted in neuroblastoma and other human cancers. Cell 1997; 90: 809-819.

42. Klanrit $P$, Flinterman MB, Odell EW, Melino G, Killick R, Norris JS et al. Specific isoforms of p73 control the induction of cell death induced by the viral proteins, E1A or apoptin. Cell Cycle 2008; 7: 205-215.

43. Kong XT, Valentine VA, Rowe ST, Valentine MB, Ragsdale ST, Jones BG et al. Lack of homozygously inactivated p73 in single-copy MYCN primary neuroblastomas and neuroblastoma cell lines. Neoplasia 1999; 1: 80-89. 
44. Melino G, De Laurenzi V, Vousden KH. p73: friend or foe in tumorigenesis. Nat Rev Cancer 2002; 2: 605-615.

45. Ueda Y, Hijikata M, Takagi S, Chiba T, Shimotohno K. New p73 variants with altered C-terminal structures have varied transcriptional activities. Oncogene 1999; 18: 4993-4998.

46. Ueda Y, Hijikata M, Takagi S, Chiba T, Shimotohno K. Transcriptional activities of p73 splicing variants are regulated by inter-variant association. Biochem J 2001; 356 (Part 3): 859-866.

47. Levrero M, De Laurenzi V, Costanzo A, Gong J, Wang JY, Melino G. The p53/p63/p73 family of transcription factors: overlapping and distinct functions. J Cell Sci 2000; 113 (Part 10): $1661-1670$.

48. Tomasini R, Mak TW, Melino G. The impact of p53 and p73 on aneuploidy and cancer. Trends Cell Biol 2008; 18: 244-252.

49. Yuan ZM, Shioya $H$, Ishiko $T$, Sun $X$, Gu J, Huang YY et al. p73 is regulated by tyrosine kinase c-Abl in the apoptotic response to DNA damage. Nature 1999; 399: 814-817.

50. Ben-Yehoyada M, Ben-Dor I, Shaul Y. c-Abl tyrosine kinase selectively regulates p73 nuclear matrix association. J Biol Chem 2003; 278: 34475-34482.

51. Murray-Zmijewski F, Lane DP, Bourdon JC. p53/p63/p73 isoforms: an orchestra of isoforms to harmonise cell differentiation and response to stress. Cell Death Differ 2006; 13: $962-972$.

52. Tomasini R, Tsuchihara K, Wilhelm M, Fujitani M, Rufini A, Cheung CC et al. TAp73 knockout shows genomic instability with infertility and tumor suppressor functions. Genes Dev 2008; 22: 2677-2691.

53. Yang A, Walker N, Bronson R, Kaghad M, Oosterwegel M, Bonnin J et al. p73-deficient mice have neurological, pheromonal and inflammatory defects but lack spontaneous tumours. Nature 2000; 404: 99-103.

54. Flores ER, Sengupta S, Miller JB, Newman JJ, Bronson R, Crowley D et al. Tumor predisposition in mice mutant for p63 and p73: evidence for broader tumor suppressor functions for the p53 family. Cancer Cell 2005; 7: 363-373.

55. Brodeur GM. Neuroblastoma: biological insights into a clinical enigma. Nat Rev Cancer 2003; 3: 203-216.

56. Douc-Rasy S, Barrois M, Echeynne M, Kaghad M, Blanc E, Raguenez G et al. DeltaNp73alpha accumulates in human neuroblastic tumors. Am J Pathol 2002; 160: 631-639.

57. Vernole P, Neale MH, Barcaroli D, Munarriz E, Knight RA, Tomasini R et al. TAp73alpha binds the kinetochore proteins Bub1 and Bub3 resulting in polyploidy. Cell Cycle 2009; 8 : 421-429.

58. Tomasini R, Tsuchihara K, Tsuda C, Lau SK, Wilhelm M, Ruffini A et al. TAp73 regulates the spindle assembly checkpoint by modulating BubR1 activity. Proc Natl Acad Sci USA 2009; 106: 797-802.

59. Grabsch HI, Askham JM, Morrison EE, Pomjanski N, Lickvers K, Parsons WJ et al. Expression of BUB1 protein in gastric cancer correlates with the histological subtype, but not with DNA ploidy or microsatellite instability. J Pathol 2004; 202: 208-214.

60. Shin HJ, Baek KH, Jeon AH, Park MT, Lee SJ, Kang CM et al. Dual roles of human BubR1, a mitotic checkpoint kinase, in the monitoring of chromosomal instability. Cancer Cell 2003 4: 483-497.

61. Sze KM, Ching YP, Jin DY, Ng IO. Association of MAD2 expression with mitotic checkpoint competence in hepatoma cells. J Biomed Sci 2004; 11: 920-927.

62. Wang X, Jin DY, Wong YC, Cheung AL, Chun AC, Lo AK et al. Correlation of defective mitotic checkpoint with aberrantly reduced expression of MAD2 protein in nasopharyngeal carcinoma cells. Carcinogenesis 2000; 21: 2293-2297.

63. Jeganathan K, Malureanu L, Baker DJ, Abraham SC, van Deursen JM. Bub1 mediates cell death in response to chromosome missegregation and acts to suppress spontaneous tumorigenesis. J Cell Biol 2007; 179: 255-267.

64. Wong S, McLaughlin J, Cheng D, Zhang C, Shokat KM, Witte ON. Sole BCR-ABL inhibition is insufficient to eliminate all myeloproliferative disorder cell populations. Proc Natl Acad Sci USA 2004; 101: 17456-17461.
65. Wong S, Witte ON. The BCR-ABL story: bench to bedside and back. Annu Rev Immunol 2004; 22: 247-306.

66. Rowley JD. Letter: a new consistent chromosomal abnormality in chronic myelogenous leukaemia identified by quinacrine fluorescence and Giemsa staining. Nature 1973; 243: 290-293.

67. Nowell PC. Discovery of the Philadelphia chromosome: a personal perspective. J Clin Invest 2007; 117: 2033-2035.

68. Pendergast AM, Gishizky ML, Havlik MH, Witte ON. SH1 domain autophosphorylation of $\mathrm{P} 210 \mathrm{BCR} / \mathrm{ABL}$ is required for transformation but not growth factor independence. Mol Cell Biol 1993; 13: 1728-1736.

69. Pear WS, Miller JP, Xu L, Pui JC, Soffer B, Quackenbush RC et al. Efficient and rapid induction of a chronic myelogenous leukemia-like myeloproliferative disease in mice receiving P210 bcr/abl-transduced bone marrow. Blood 1998; 92: 3780-3792.

70. Zhang X, Ren R. Bcr-Abl efficiently induces a myeloproliferative disease and production of excess interleukin-3 and granulocyte-macrophage colony-stimulating factor in mice: a novel model for chronic myelogenous leukemia. Blood 1998; 92: 3829-3840.

71. Deininger MW, Goldman JM, Melo JV. The molecular biology of chronic myeloid leukemia Blood 2000; 96: 3343-3356.

72. Kharbanda S, Ren R, Pandey P, Shafman TD, Feller SM, Weichselbaum RR et al. Activation of the c-Abl tyrosine kinase in the stress response to DNA-damaging agents. Nature 1995; 376: 785-788.

73. Yuan ZM, Huang Y, Ishiko T, Kharbanda S, Weichselbaum R, Kufe D. Regulation of DNA damage-induced apoptosis by the c-Abl tyrosine kinase. Proc Natl Acad Sci USA 1997; 94: 1437-1440.

74. Wang X, Babu JR, Harden JM, Jablonski SA, Gazi MH, Lingle WL et al. The mitotic checkpoint protein $\mathrm{hBUB} 3$ and the mRNA export factor $\mathrm{hRAE} 1$ interact with GLE2p-binding sequence (GLEBS)-containing proteins. J Biol Chem 2001; 276: 26559-26567.

75. Blasco MA, Lee HW, Hande MP, Samper E, Lansdorp PM, DePinho RA et al. Telomere shortening and tumor formation by mouse cells lacking telomerase RNA. Cell 1997; 91: 25-34.

76. Reilly PT, Wysocka J, Herr W. Inactivation of the retinoblastoma protein family can bypass the HCF-1 defect in tsBN67 cell proliferation and cytokinesis. Mol Cell Biol 2002; 22: $6767-6778$.

77. Kranc KR, Bamforth SD, Braganca J, Norbury C, van Lohuizen M, Bhattacharya S. Transcriptional coactivator Cited2 induces Bmi1 and Mel18 and controls fibroblast proliferation via Ink4a/ARF. Mol Cell Biol 2003; 23: 7658-7666.

78. Kitagawa K, Skowyra D, Elledge SJ, Harper JW, Hieter P. SGT1 encodes an essential component of the yeast kinetochore assembly pathway and a novel subunit of the SCF ubiquitin ligase complex. Mol Cell 1999; 4: 21-33.

79. Lamb JR, Tugendreich S, Hieter P. Tetratrico peptide repeat interactions: to TPR or not to TPR? Trends Biochem Sci 1995; 20: 257-259.

80. Panaretou B, Siligardi G, Meyer P, Maloney A, Sullivan JK, Singh S et al. Activation of the ATPase activity of hsp90 by the stress-regulated cochaperone aha1. Mol Cell 2002; 10: 1307-1318.

81. Tugendreich S, Tomkiel J, Earnshaw W, Hieter P. CDC27Hs colocalizes with $\mathrm{CDC} 16 \mathrm{Hs}$ to the centrosome and mitotic spindle and is essential for the metaphase to anaphase transition. Cell 1995; 81: 261-268.

82. Yoda K, Nakamura T, Masumoto H, Suzuki N, Kitagawa K, Nakano M et al. Centromere protein B of African green monkey cells: gene structure, cellular expression, and centromeric localization. Mol Cell Biol 1996; 16: 5169-5177.

83. Niikura Y, Ohta S, Vandenbeldt KJ, Abdulle R, McEwen BF, Kitagawa K. 17-AAG, an Hsp90 inhibitor, causes kinetochore defects: a novel mechanism by which 17-AAG inhibits cell proliferation. Oncogene 2006; 25: 4133-4146.

84. Bansal PK, Mishra A, High AA, Abdulle R, Kitagawa K. Sgt1 dimerization is negatively regulated by protein kinase CK2-mediated phosphorylation at Ser361. J Biol Chem 2009; 284: 18692-18698. 